


$$
\begin{aligned}
& \text { (1. } \\
& \text { (6) }
\end{aligned}
$$


Digitized by the Internet Archive in 2011 with funding from

LYRASIS members and Sloan Foundation

http://www.archive.org/details/tobaccosubstatio1937ande 




\title{
TOBACCO SUBSTATION AT WINDSOR REPORT FOR 1936
}

\author{
P. J. ANDERSON \\ T. R. SWANBACK AND O. E. STREET
}

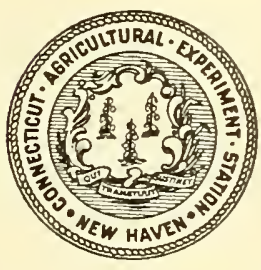

\section{(Timmettiout}

\section{Anrtultural Finperiment Station}

\section{Nieu Thatuen}


BOARD OF CONTROL

His Excellency, Governor Wilbur L. Cross, ex-officio, President

Elijah Rogers, Vice-President. . . . . . . . . . . . . . . . . . . . . Southington

William L. Slate, Director and Treasurer . . . . . . . . . . . . . . . New Haven

Edward C. Schneider, Secretary . . . . . . . . . . . . . . . . . Middletown

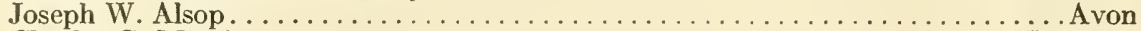



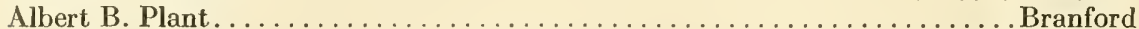

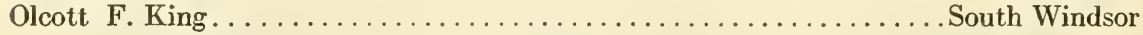

\section{STAFF}

Administration.

Analytical Chemistry.

Biochemistry.

Botany.

Entomology.

Forestry.

Plant Breeding.

Soils.

Tobacco Substation at Windsor.
William L. State, B.Sc., Director and Treasurer.

Miss L. M. Brautlecht, Bookkeeper and Librarian.

Miss Katherine M. Palmer, B.Litt., Editor.

G. E. GrahaM, In Charge of Buildings and Grounds.

E. M. Bailey, Ph.D., Chemist in Charge.

C. E. Shepard

OWEN L. NOLAN

Harry J. Fisher, Ph.D. Assistant Chemists.

W. T. MATHIS

DAvid C. WALDEN, B.S.

Miss Janetha Shepard, General Assistant.

Chas. W. Sonerrerg, Laboratory Assistant.

V. L. Churchul, Sampling Agent.

Mrs. A. B. Vosburgh, Secretary.

H. B. Vrckery, Ph.D., Biochemist in Charge.

George W. Pucher, Ph.D., Assistant Biochemist.

G. P. Cunnton, Sc.D., Botanist in Charge.

E. M. Stoddand, B.S., Pomologist.

Miss Florence A. McCormick, Pн.D., Pathologist.

A. A. Dunlap, PH.D., Assistant Mycologist.

A. D. McDonnele, General Assistant.

Mrs. W. W. Kelsey, Secretary.

W. E. Britton, Ph.D., D.Sc., Entomologist in Charge, State Entomologist.

B. H. WALDEN, B.AgR.

M. P. ZAPPE, B.S.

Philip Garman, Ph.D. Assistant Entomologists.

Roger B. Friend, Ph.D.

NEely TunNen, M.A.

JoHN T. Ashworth, Deputy in Charge of Gypsy Moth Control.

R. C. BotsFord, Deputy in Charge of Mosquito Elimination.

J. P. Johnson, B.S., Depuly in Charge of Japanese Beetle Control.

$\left.\begin{array}{l}\text { Miss Helen A. Hulse } \\ \text { Miss BetTy Scoville }\end{array}\right\}$ Secrelaries.

Walter O. Filley, Forester in Charge.

H. W. Hrcock, M.F., Assistant Forester:

J. E. Rrley, Jr., M.F., In Charge of Blister Rust Control.

Miss Pauline A. Merchant, Secretary.

Donald F. Jones, Sc.D., Geneticist in Charge.

W. Ralph Singleton, Sc.D., $\}$ Assistant Geneticists.

M. F. Morgan, Pн.D., Agronomist in Charge.

H. G. M. Jacobson, M.S., | Assistant Agronomists.

Herbert A. Lunt, Ph.D., Assistant
Dwight B. Downs, General Assistant.

Miss Geraldine Everet, Secretary.

Paul J. Andenson, Pr.D., Pathologist in Charge.

T. R. Swandack, M.S., Agronomist.

O. E. Street, Ph.D., Plant Physiologist.

C. E. Swanson, Laboratory Technician.

Miss Dorothy Lenaro, Secretary. 


\section{CONTENTS}

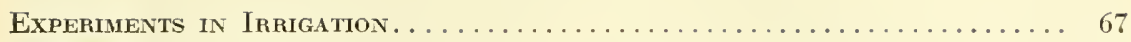

Further Experinents on Time of Harvesting Havana Seed Tobacco.... 73

Soybean Oil Meal as a Tobacco Fertilizer.................. 75

Single Sources Versus Mixed Sources of Nitrogen in the Fertilizer... 78

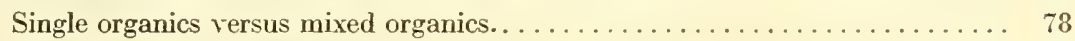

Nitrate starter in the mixture. . . . . . . . . . . . . . . . . 79

Fractional Applications of Nitrate of Soda............... 82

Experiments on Control of Tobacco Insects in 1936.............. 84

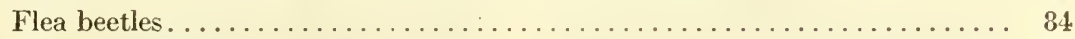

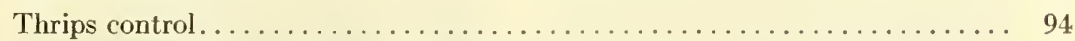

Abundance of various species of insects..................... 96

Studies on the Anatony of the Tobacco Leaf. I. The Midrib........ 98

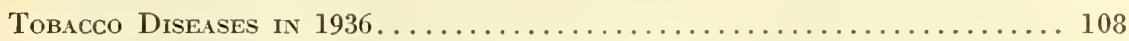

Observations and notes on prevalence of diseases................ 108

Studies of Pole-rot. II. Vein-rot....................... 112

Broadleaf Fertilizer Experiments........................... 118 

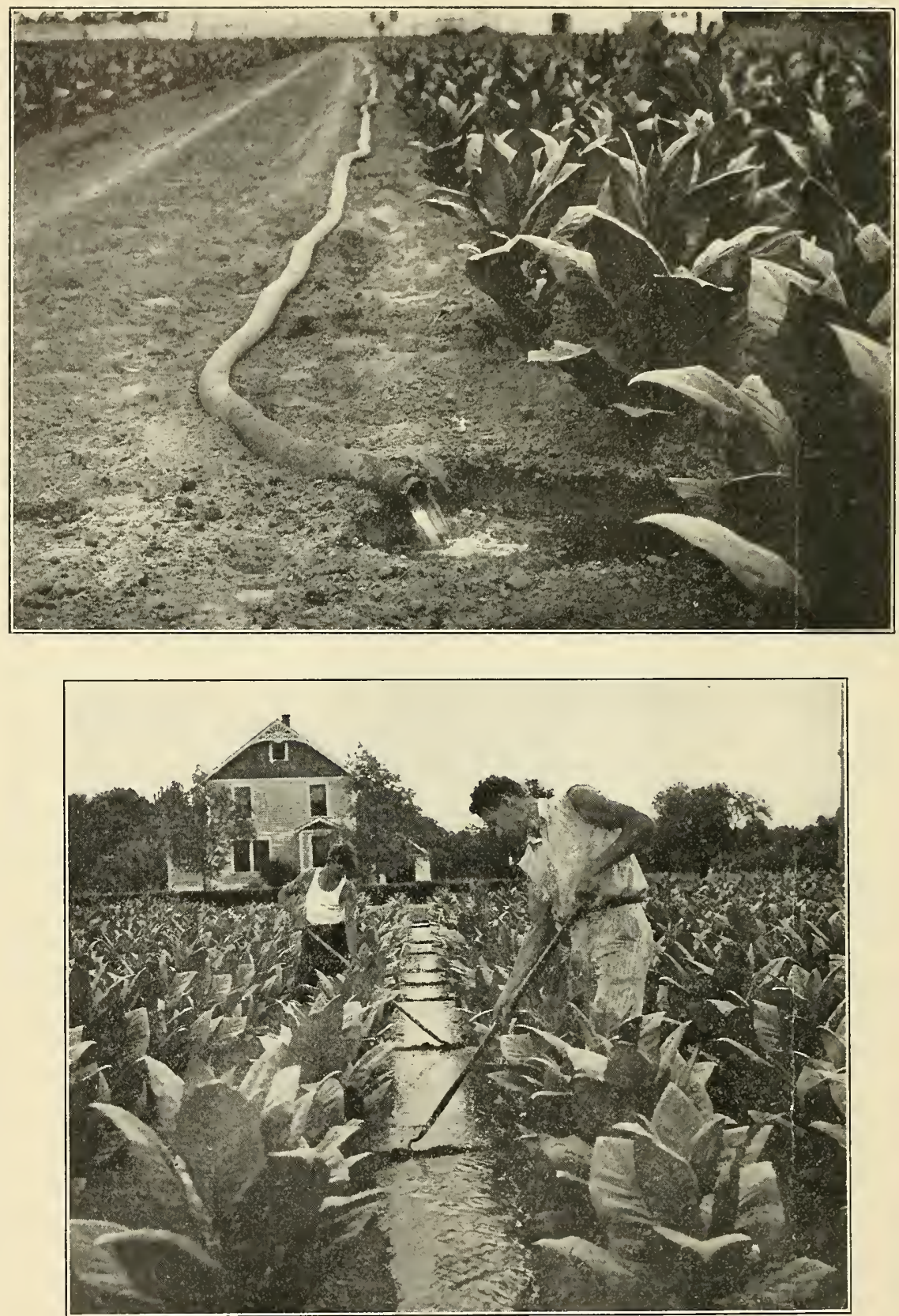

IRRIGATION

Figure 1. Water flows to the upper end of the row through a four-inch hose.

Figure 2. Small dams in the row prevent the whole volume of water from flowing rapidly to the lower end of the field, thus giving an even distribution along the row. 


\title{
TOBACCO SUBSTATION AT WINDSOR
}

\author{
Report For 1936
}

\author{
P. J. Anderson, T. R. Swanback and O. E. Street
}

T

HIS, THE FIFTEENTH annual report of the Tobacco Substation, records the progress of investigations on fertilization, cultural operations and control of insects and diseases of the tobacco crop. Two types of investigations are always in progress at this Station. The first comprises empirical tests with exact measurements of results which are immediately applicable in commercial practice. Such, for instance, are the tests of different insecticides for the control of flea beetles as recorded in this bulletin. The second type includes more fundamental studies, the results of which are usually not directly applicable to commercial tobacco growing but are necessary for an understanding and intelligent conduct of the more practical tests of the first type. Into this group come the studies on the anatomy of the tobacco leaf.

Most of our projects include both practical tests and fundamental investigations. The latter are usually more time-consuming and perhaps more important, although less is published about them. They may lead to more extensive changes in practice than the empirical lests. There is need, however, for both types in any well-rounded progran planned for the improvement of Connecticut Valley tobacco.

One important addition to the research staff has been made at the Tobacco Substation during the year. Due to the increasing serionsmess of some of the insect pests of tobacco, particularly flea heetles, thrips and wire worms, the United States Department of Agriculture through the Bureau of Entomology and Plant Quarantine assigned a full time entomologist to this section, Mr. Austin W. Morrill, Jr., who started work on July 1. He has permanent quarters at the Substation and is coöperating with the staff entomologist, Mr. Donald S. Lacroix, who is located at Windsor only during the summer. This coöperation lıas been very satisfactory in speeding up the development of control methods, particularly for flea beetles. The results of their joint investigations for 1936 are summarized later in this report.

It will be noted that less space than usual is devoted to fertilizer experiments. This is partly because the staff is spending more time on other lines of imvestigation, and also because there is in process of preparation a special bulletin on nilrogen fertilization of tobacco. The new bulletin will review the results of nitrogen experiments that have occupied the major place on our farm during the last few years, and bring together under one cover the results of all previous experiments dealing with fertilizer nitrogen for tobacco. Since we hope to have it completed and ready for publication in $193 \pi$, it seems unnecessary to devote much space to the subject here.

In the following pages, we discuss for the first time the subject of irrigation of tobacco, a practice which has many proponents and some opponents among the practical growers. For a number of years, whenever 
the season was sufficiently dry, experiments on irrigation have been conducted at the Substation. Until 1936, the results were somewhat disappointing and contradictory and could not be fully explained. Therefore nothing was published. The experiments in 1936 explain the previous poor results and indicate a method of avoiding them.

The rainfall for May, June and July, 1936, was below normal. However, in general, the prevailing weather favored the growth of crops, except for one dry, very hot period during the first three weeks of July. Our own crop as well as that of most growers in the Valley was of good quality and heavy yield. The dry weather during July necessitated one irrigation. Additional water was applied on the special irrigation plots.

Table 1. Distribution of Rainfall in Inches at the Tobacco Substation, Windsor 1922-1.936

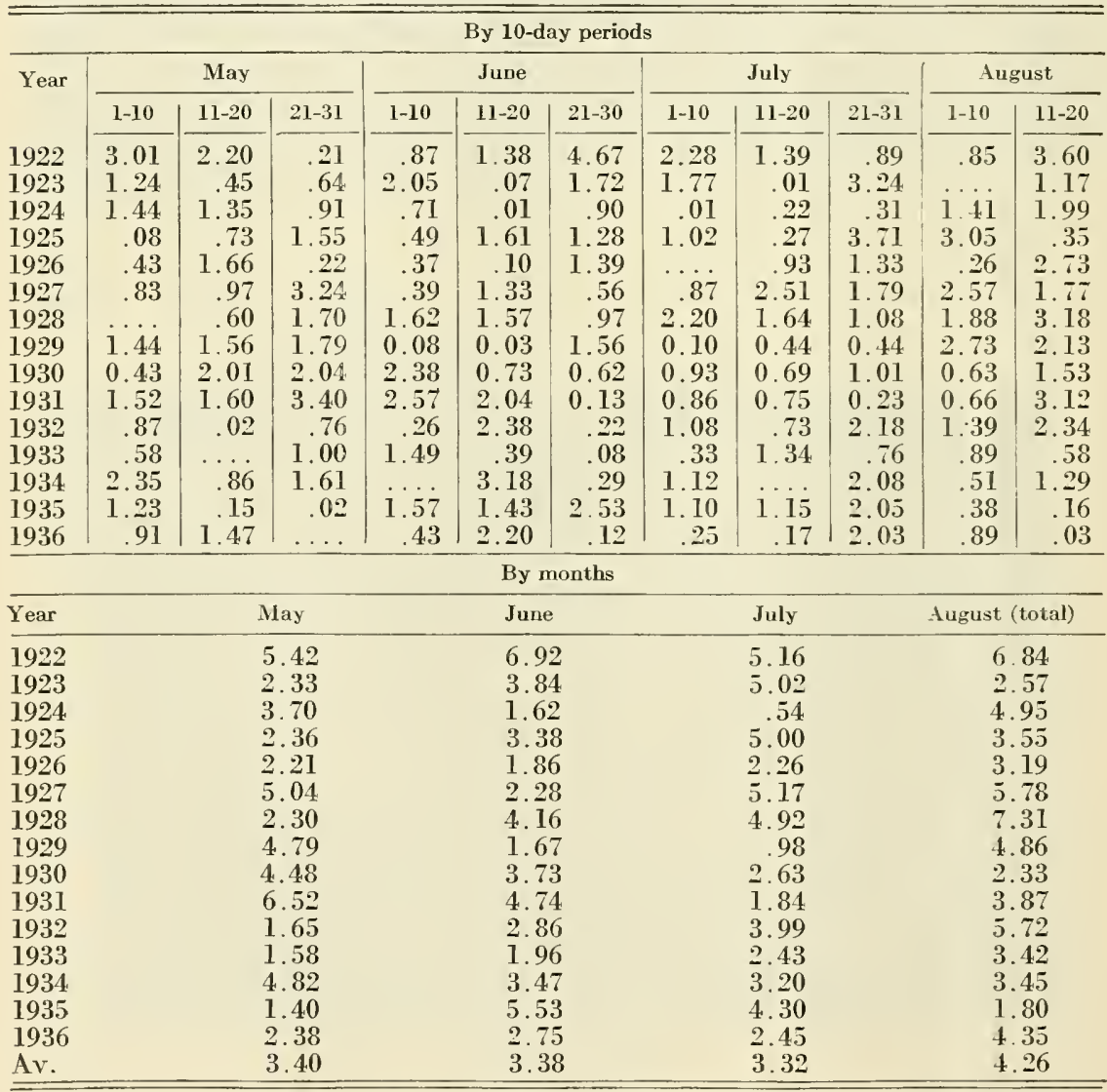

In the above table is shown the amount of rainfall by 10-day periods during the growing season for tobacco and, for comparison, the rainfall of the same periods during the previous 14 years at this Station. 


\section{EXPERIMENTS ON IRRIGATION}

Growers and dealers are aware that the highest quality of tobacco is grown on light, sandy land, provided the season is favorable. However, when there is not sufficient rainfall during the summer, tobacco on this type of soil suffers more than that on other types. Moreover, such soils are not favorable in a very wet year because, with excessive rainfall, the nitrogen leaches away more rapidly than on heavy soils and a starved, yellow crop of light weight and poor quality results.

On account of the uncertainty of getting a good crop except during very favorable years-which are not too frequent here-many of the potentially best soils are no longer planted to tobacco. They are either abandoned to weeds and brush or turned over to less expensive and less profitable crops. The grower feels that he cannot take too many risks in view of the high cost of growing tobacco: $\$ 200$ to $\$ 300$ to the acre for outdoor tobacco and $\$ 500$ to $\$ 700$ for shade. Therefore, he is prone to cultivate the heavier soil where he feels more confident of getting a crop every year although he knows it may not have a good color and quality. During very dry seasons, even the tobacco on more favorable soils suffers from drought.

In dry year crops, the leaves are shorter, thicker and darker. The percentage of darks, tops and fillers is increased, with corresponding decrease in the more profitable, better grades. There is also an impairment in burn, taste and aroma. The buyer is not eager to purchase such crops and naturally the price offered is lower.

In view of the great losses in dry years, it is not surprising that at various times and places in the Connecticut Valley growers have attempted to irrigate the suffering crops. Every serious drought year is followed by widespread installation of irrigation systems. Such a period is usually succeeded by a series of wet years during which the systems fall into disrepair or are abandoned so that the next drought year finds the grower as unprepared as before. He watches the sand grow drier and drier, hoping every night that it will rain within the next 24 hours; he delays from day to day and finally starts to irrigate after the damage is done. Some have abandoned irrigation because either they did not realize any improvement in the crop or they believed that irrigation did more harm than good.

The total result is that at present only a few of the farms are equipped for irrigation. Some of them no longer use the apparatus they have. There is no uniformity of practice, of method, or of opinion as to the benefits derived. Consequently, irrigation is not a recognized routine operation here. Nothing has been published about irrigation of tobacco by the experiment stations of New England and very little from stations in other tobacco sections.

Various methods of conducting water to the fields and of applying it to the plants have been used and nothing would be gained by describing them. The stationary overhead sprinkling system has been tried perhaps least of all, and is not practiced anywhere now. It is expensive and the poles used to support the pipes interfere with plowing and other cultural 
operations. Although it most nearly duplicates a natural rain and gives the best distribution of water, it is subject to the objection that it might spread leaf diseases that are present in the field.

In most of the methods that have been tried, the water is brought to the high points of the field and allowed to run down the slope in the furrow between the rows. Since the rows are hilled up a little more at each cultivation, there is always such a natural pathway for the water, which soaks into the soil and is taken up by the roots as it flows along. This does not distribute the water as uniformly as a sprinkler method because the soil in the top of the ridge remains dry. But an even distribution is probably not necessary because the roots grow laterally with such rapidity that those from plants in adjacent rows meet midway by the time the tobacco is a foot high. These laterals are able to take up sufficient water to supply the plants' needs, as shown by the recovery of wilted leaves within a half-hour after irrigation. Unless the slope of the land is very gentle, it is customary to build dams at intervals across the furrow. Thus the water will not rum too rapidly to the lower end but will have time to soak down (Figure 2, page 64).

The water is drawn from neighboring ponds or brooks, usually by electric or gasoline-driven pumps, through either large fire hose or metal pipes. The latter may be a permanent system buried underground, or a movable system of surface galvanized pipes with patented joints where the sections can be quickly attached or removed.

\section{Plan of Experiment}

Since water is obviously the limiting factor in producing a crop on such land in a dry season, it seems reasonable to expect a good crop if sufficient water can be supplied artificially at the right time. An experiment was planned to make a thorough test of this hypothesis and to obtain statistical data on the effect of irrigation on the yield and quality of leaf. Accordingly a field test was laid out in 1930 with the intention of contimuing it each dry year.

Field $I$ on the station farm was selected for this experiment because the soil is most sandy (Merrimac sandy loam) and the effects of drought are always apparent there first and are more pronounced. This is the type of field which the grower would be most likely to irrigate. It usually yields a light crop, but of excellent quality if the season is just right.

The plan of the test has varied somewhat from year to year but in general consists of laying out similar plots, five to ten rows wide, side by side, and irrigating the alternate plots as often as the season seems to require. No definite time for applying the water, and no estimate of intervals between applications, can be determined beforehand, as one must be guided by the season. An effort was made to apply the water before there was any serious drought injury rather than to wait until the shortage was acute and the growth impulse stopped. Water was supplied from a hydrant, conducted to the higher end of the field through four-inch fire hose and allowed to flow slowly down between the rows as described above (Figure 1). Soil dams at intervals were used to prevent too rapid flow (Figure 2). The slope of the field is fairly uniform and all in one direction. The quantity of water applied each time was measured by a meter at the hydrant. 
Preliminary tests of 1930. During this year there were ten onefortieth acre plots, five of which were irrigated. During the latter half of July it was very dry and hot. The tobacco wilted badly and stopped growing. Water was applied on July 19, 23 and 27. The irrigated tobacco recovered quickly; the leaves appeared larger and the growth excellent in contrast with the non-irrigated plots. From the striking differences noted in the field, one would judge that irrigation had greatly increased the value of the tobacco. But when the cured leaves were graded and weighed in the sorting shop, the amount of improvement was disappointingly small. The average increase in yield for the five plots was only 67 pounds to the acre and the increase in grading less than 5 percent (approximately one cent a pound). The total benefit hardly paid for the cost of irrigation.

Test of 1934. The next favorable opportunity for continuing the test was in the very dry year of 1934. During this season the field was divided into a lower and an upper tier of plots so that there were irrigated and non-irrigated plots at each end. In irrigating, however, the water was turned into the rows at the upper end, and flowed first through the upper tier, and then down over the lower tier. July was dry and hot; water was applied on the tenth, seventeenth and twenty-fourth. Rains started on the twenty-sixth and no further irrigations were necessary. The quantity of water applied at each irrigation was about equal to a rainfall of 1.5 inches.

As in the previous experiment, the tobacco on the irrigated plots grew and spread better; the leaves appeared larger and more luxuriant. During the latter part of the month, however, the plants on the irrigated plots appeared paler, and in the upper tier took on a yellowish cast indicative of nitrogen starvation. Soil tests also showed that the nitrates had almost disappeared from the irrigated plots. All were harvested on August 6. The sorting and yield records (average) of the plots on the two tiers were:

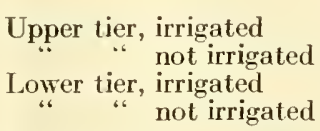

Pouuds per acre
1594
1701
1907
1836

At first glance the results appear to be contradictory since the lower tier shows the reverse of the upper tier. On the upper part, the irrigated tobacco was yellow, dead and not suitable for manufacture of cigars, with all the symptoms of nitrogen-starved tobacco. Both the yield and the grade index were far below those on the non-irrigated plots, although the tobacco on these latter plots was not very good, the leaves being heavy, short and thick, but not dead or yellow. On the lower part of the field there was good tobacco on both the irrigated and non-irrigated plots, but both the yield and the grade index were superior on the irrigated plots. The explanation of these apparently inconsistent results is probably that the water carried a part of the nitrates from the upper plots and deposited them in the lower end of the field. Thus a larger yield resulted there. 
The most important result of the experiment of that year was that it demonstrated the important bearing of leaching of plant nutrients on the practice of irrigation by this method on this type of soil. This and other soil tests and observations on irrigated tobacco showed that irrigation on sandy land may easily do more harm than good if the factor of leaching is disregarded. This suggested an explanation of the negative results of previous irrigation tests. It introduced an entirely new angle to the irrigation experiment and future tests were planned with the object of measuring and controlling this factor.

Test of 1936. In the experiment of 1936, there were 18 rows, each 200 feet long. Six rows were not irrigated; six were irrigated in the usual way; six others were irrigated with the addition of nitrate. The method of supplying the nitrate was as follows: Before the stream of water is turned into the head of the row, small dams five or six inches high are built with a hoe at intervals of about 20 feet-depending on the pitch of the slope-in the furrow. The accumulated head of water back of the dam soon breaks it through, and in about 15 or 20 minutes it reaches the lower end of the row. Then the operator passes quickly back through the row, rebuilding the broken dams so that there is standing water through the whole length of the row (Figure 2). At this point nitrate of calcium, at the rate of 100 pounds to the acre, is distributed by hand in the row. It dissolves immediately in the water. As the water soaks down to the roots, it carries sufficient nitrate to replace any that is lost by leaching and it is quickly absorbed by the plants. The steps in the method of irrigation are the same in both cases except for the addition of nitrate to six of the rows.

The weather during July was very dry and hot. Before wilting was very pronounced, however, the first water was applied on July 9 at a rate equivalent to 2 inches of rain. The non-irrigated rows wilted badly during the next week and many leaves were sun-burned. On the seventeenth, the second irrigation was applied at the rate of 1.5 inches. Rains beginning on the twenty-fourth made further irrigation unnecessary.

Table 2. Irrigation Plots. Pounds of Nitrate Nitrogen (N) Per Acre IN THE Surface SoIL

\begin{tabular}{|c|c|c|c|c|}
\hline \multicolumn{2}{|r|}{ Date of sampling } & \multirow{2}{*}{$\frac{\begin{array}{c}\text { Not } \\
\text { irrigated }\end{array}}{100}$} & \multirow{2}{*}{$\begin{array}{c}\begin{array}{c}\text { Irrigated } \\
\text { alone }\end{array} \\
100\end{array}$} & \multirow{2}{*}{$\begin{array}{c}\begin{array}{c}\text { Irrigated } \\
\text { and nitrate } \\
\text { added }\end{array} \\
100\end{array}$} \\
\hline July & 8. Before any irrigation & & & \\
\hline July & 13. Four days after first irrigation & 71 & 12 & 47 \\
\hline July & 21. Four days after second irrigation & 26 & 6 & 56 \\
\hline Augus & 3. Nine days before harvest & 24 & 8 & 36 \\
\hline Augus & 10. Two days before harvest & 30 & 19 & 37 \\
\hline
\end{tabular}

Differences in appearance of the plants were as striking as in previous years, the irrigated plots showing larger and more luxuriant growth. About 10 days before harvest, the irrigated plot which had not received the nitrate treatment showed signs of nitrogen shortage. The leaves 
appeared a little paler in color and this difference increased until harvest. The leaves on the nitrate plot seemed larger and did not show signs of ripening so quickly as those on the plot that was irrigated only.

In order to follow the variation in the available nitrogen supply in the soil during the season, the soil in each plot was tested before the experiment was started, again a few days after each irrigation, and finally a week before harvest. The results presented in Table 2 confirm the observations on the color of the leaves and also show how effectively the addition of nitrate of calcium keeps up the supply of available nitrogen in the soil. Previous tests and observations lead us to believe that for proper growth of tobacco the soil should always show a mininum of 20 pounds of nitrate nitrogen to the acre. It will be noted from Table 2 that the only samples here that showed a nitrogen content lower than 20 pounds were those taken from the plot that was irrigated only-and this was the only place where the tobacco showed starvation symptoms.

The tobacco was harvested from all plots on the same day, August 12, cured together in the same shed and graded at the station sorting shop by commercial graders. The yield and grading records are presented in Table 3. Outside the grading records, the following observations made at the time the tobacco was on the sorting bench are of interest:

No irrigation. Leaves dark, heavy and short. No yellow leaves.

Irrigation only. Many of the leaves yellow, dead, chaffy-typical nitrogen starvation. Leaves longer than on the non-irrigated plot and not so thick.

Irrigation plus nitrate. Excellent quality, bright color, neither yellow and chaffy, nor dark and heavy.

Table 3. Irrigation Tests in 1936. Yield and Sorting Records

\begin{tabular}{|c|c|c|c|c|c|c|c|c|c|c|}
\hline \multirow[t]{2}{*}{ Treatment } & \multirow{2}{*}{$\begin{array}{l}\text { Acre } \\
\text { yield }\end{array}$} & \multicolumn{8}{|c|}{ Percentage of grades } & \multirow{2}{*}{$\begin{array}{l}\text { Grade } \\
\text { index }\end{array}$} \\
\hline & & $\mathbf{L}$ & $M$ & LS & Ss & LD & DS & $\mathrm{F}$ & B & \\
\hline No irrigation & 2114 & 1 & 3 & 18 & 6 & 51 & 8 & 11 & 2 & 336 \\
\hline Irrigation & 1937 & 2 & 6 & 22 & 4 & 36 & 8 & 10 & 12 & .346 \\
\hline Irrigation+nitrate & 2152 & 10 & 14 & 19 & 4 & 39 & 4 & 8 & 2 & 445 \\
\hline
\end{tabular}

Some points of interest brought out in the table are also worthy of mention:

Irrigation alone has reduced the yield by almost 200 pounds. This agrees with the well known fact that a dry year crop usually has a surprisingly high poundage, explained by the thickness of the leaves.

Also the very high percentage of dark leaves ( 59 percent on the nonirrigated plot) is characteristic of a dry weather crop. This objectionable feature has been reduced in both the other plots.

The percentage of brokes is highest on the irrigated (alone) plot. These brokes were the yellow, dead leaves mentioned above.

The addition of nitrate at time of irrigation has not greatly increased the yield as compared with the non-irrigated tobacco. It has, however, very materially improved the grading (increase of about 33 percent) by increasing the percentage of the more valuable grades and the size of the leaves. 
Conclusions and Discussion. These experiments were conducted on light, sandy soil with a coarse, sandy subsoil, the kind that always suffers from drought and from leaching. This character of the soil should be kept in mind in interpreting results. Our own experience with irrigation on heavier soils on the station farm has taught us that irrigation (without addition of nitrate) can be practiced up to a certain point without serious injury from leaching. But the grower who has his tobacco on heavier, more retentive soils does not often resort to irrigation. It is soils similar to those on which these experiments were conducted that the grower is most apt to irrigate because these show the effect of water shortage first. Probably irrigation has never become a regular practice in growing tobacco here, because the grower experimented on such soils and failed to reap the benefits he expected. Therefore he resigned himself to taking the weather as it came, his losses in dry years, and trusting to the Lord that conditions would be better next time.

These experiments show why lie failed and how he can succeed. Most growers have a supply of water close at hand and the equipment for transporting it to the field is not too expensive when compared with the benefits. During hot, midsummer droughts his labor is usually idle because little can be done on the farm till the rain comes. Therefore the increase in labor expense is little or nothing. It is a common axiom that 90 percent of the grower's success in getting a crop depends on the weather, and corollary to this: That you can't do anything about the weather. Like most axioms, this one is only relatively true. The grower cannot change the weather but he can change the effect of it almost completely by intelligent irrigation.

If heavy irrigation must be resorted to, the application of nitrate is just as important as the addition of water. Up to the present, no bad effects of irrigation plus nitrates on the quality or burn of the tobacco have been discovered. Such tobacco has been of unusually high quality, as would be expected on this type of land in a favorable year without irrigation. In fact, there seems now to be no reason why we cannot produce both a high yield and high quality on dry, sandy lands of this type.

Further experimentation is necessary to determine the optimum quantity of nitrate to apply and to find more convenient methods of application.

Other nitrates, such as nitrate of soda, would probably give the same results as nitrate of calcium. Also it might be more convenient to add the nitrate to the water at the point where it comes out of the pipes or hose. 


\section{FURTHER EXPERIMENTS ON TIME OF HARVESTING HAVANA SEED TOBACCO}

This experiment was begun in 1935 to determine how long Havana Seed tobacco should be left in the field after topping, and to measure the effects of earlier or later harvesting on yield, size, quality and chemical composition of the leaves. The results of the first season were presented in the annual report for 1935 (Com. Agr. Exp. Sta. Bul 386: 585-587). In 1936 the method of procedure was the same but the experimental plots were located on a different field (No. XI) which is more farorable for growth and leaches less than Field $V$ where the experiment was placed in 1935. The two seasons were also somewhat different in that there was an excess of rainfall in 1935 which caused a starved condition of the leaves, while in 1936 there was not sufficient rainfall and it was necessary to irrigate the field once (July 15).

The plants were set on June 2. The fertilizer used was an arerage good formula with cottonseed base, supplying 200 pounds of nitrogen, 60 pounds of phosphoric acid, 200 pounds of potash and 100 pounds of magnesia to the acre. The plants grew very rapidly and continuously and all appeared quite uniform at time of topping, July 2-. The rows were 165 feet long, each containing about 110 plants. Three rows were harvested one week after topping, August 3; three others, two weeks after topping; and three more, three weeks after topping. All were cured in the same tier of the same shed and were sorted in the station sorting room by commercial graders in November.

The sorting and yield records are shown in Table 4.

Table 4. Expenuments on Time of Harvesting. Sorting and lield Reconds Fon 1936

\begin{tabular}{l|c|c|c|c|c|c|c|c|c|c|c|c}
\hline \hline \multirow{2}{*}{ Time of harvesting } & $\begin{array}{c}\text { Yield in } \\
\text { pounds } \\
\text { per acre }\end{array}$ & \multicolumn{7}{|c|}{ Percentage of grades } & Grade \\
index
\end{tabular}

Notes on the condition and appearance of the leaves at time of sorting were as follows:

One week. Thinnest of all. Good quality, but of a decided greenish cast.

Two weeks. Good quality but somewhat veiny, especially the seconds.

Three weeks. Excellent quality with good color and body; not veiny. No greenish cast.

Table 5 shows the effect of the longer period of ripening on the length of the leaves. The same thing is shown graphically in Figure 3. It is apparent from this that there is a marked and continuous expansion in leaf size after topping up to at least three weeks. Although no actual measurements of leaf thickness were made, observations on the cured leaves give the impression that the mature leaves are thicker (have more "body") than those harvested a week after topping. 
The most striking fact shown in the data presented is the enormous increase in weight during the three weeks after topping. During the second week there was an increase of 318 pounds to the acre, and during the third, another 232 pounds. The total for these two weeks amounted

Table 5. Percentage of Crop in Different Lengths of Leaf. 1936.

\begin{tabular}{l|r|r|r|r|r|r|r}
\hline \hline \multirow{2}{*}{ Time harvested } & \multicolumn{8}{|c}{ Length in inches } \\
\cline { 2 - 7 } & $15^{\prime \prime}$ & $17^{\prime \prime}$ & $19^{\prime \prime}$ & $21^{\prime \prime}$ & $23^{\prime \prime}$ & $25^{\prime \prime}$ & $27^{\prime \prime}$ \\
\hline One week after topping & 3 & 9 & 16 & 24 & 30 & 18 & 0 \\
Two weeks after topping & 1 & 5 & 10 & 20 & 25 & 26 & 13 \\
Three weeks after topping & 1 & 3 & 8 & 16 & 26 & 33 & 13 \\
\hline \hline
\end{tabular}

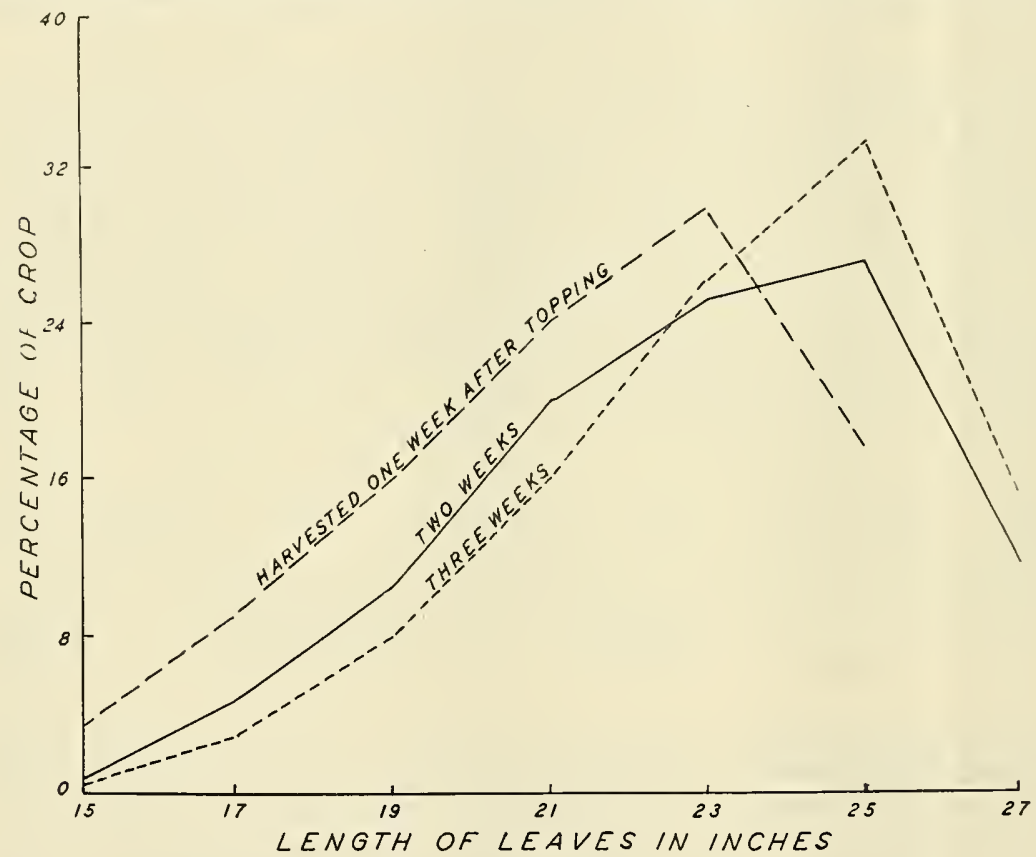

Figure 3. Leaf length as affected by time of harvesting.

to 29 percent increase. Similar changes in weight were noted in the experiment of 1935. According to analyses made on the crop of 1935, this is not due to any accumulation of mineral salts in the leaves (as expressed in percentage of dry weight). It can be accounted for only on the basis of the broader-surface area and thickness of the leaves. Possibly there may be some increase in the organic constituents, for which no analyses have yet been made. Also there has been no attempt to measure the size of veins to see whether they enlarge. Investigation by Avery ${ }^{1}$ shows that although there is an increase in the vascular

${ }^{1}$ Avery, George S. Structural responses to the practice of topping tobacco plants. Bot. Gaz. 96: 314-329. 1934. 
tissues of the veins after topping, it is only in proportion to the expanding leaf surface.

The best grade index, by a slight margin, was obtained on the tobacco that was left standing longest in the field. The actual improvement in quality is undoubtedly greater, however, than is indicated by the grade index. The tobacco harvested last had more the color and appearance of "ripe" tobacco, a quality desired by the manufacturers.

In one respect, the results of 1936 are at variance with the results of 1935. During the previous year there was a distinct drop in grade index at the end of the third week, due to a high percentage of yellow, starved leaves. This was clearly caused by a combination of a wet year and the more leachy soil on which the plots were located in 1935.

The experiments up to the present indicate that the grower will profit greatly by leaving the tobacco in the field for at least three weeks after topping, except when he is confronted with the danger of starvation on account of excessive rainfall, too little fertilizer, or a soil that is not sufficiently retentive.

\section{SOYBEAN OIL IIEAL AS A TOBACCO FERTILIZER}

In the last 15 years the soybean has become a crop of considerable importance in the United States. The land devoted to soybeans for oil production in 1936 was about 1.5 million acres and this is expected to increase well beyond 2 million acres in 1937. Production of meal will probably be close to one million tons. Soybeans are grown principally for the oil that is extracted from them. The meal that is left after the oil is extracted is a less valuable by-product which has found a limited use in human foods, animal feeds and various industrial articles. With ever increasing acreage, however, additional uses for the surplus meal should be found.

In the Orient, soybean oil meal has been used for centuries as a fertilizer, but in this country little attention has been given to this possibility. The composition of the meal is very similar to that of cottonseed meal, containing about 7 percent nitrogen, 1.7 percent phosphoric acid and 2.5 percent potash. It should, therefore, theoretically make a good substitute for the popular cottonseed product. Furthermore, since the production of meal is steadily increasing and has all the appearance of being a permanent commodity in the future, it should also compete in price with the other meals.

There are no published accounts of experiments in which it has been tested as a tobacco fertilizer. The experiments herein recorded were begun with the object of testing this material as the only source of nitrogen in the tobacco fertilizer formula, comparing it with other standard meals and observing the effects on yield, grading and quality of the leaf.

There are three common methods of extracting the oil from the bean, namely: The hydraulic, the expeller and the solvent processes. The oldest is probably the hydraulic process whereby simply the exerted pressure extracts the oil. 
In the expeller process, the beans first pass through a grinder, and then are subjected to high pressure and friction to expel the oil.

For the solvent process, some chemical solvent is used, such as ether, naphtha, benzol or hexane, to extract the oil. Afterward the meal is well dried through steaming, and whatever solvent is used is thereby evaporated.

Oil meal from the expeller process was included in our experiments for the first time in 1935. The results were briefly reported in Bulletin 386 of the Connecticut Agricultural Experiment Station. Because of the favorable outcome that year, the experiments were expanded in 1936 and oil meal from the solvent process was also included.

The single plot on Field V was continued in 1935. Soybean oil meal from the expeller process was again used here. In both yield and grading the results surpassed those in which any other organic carrier was used in this series. It produced a leaf with an excellent "finish", meaning ample stretch, perfect texture and a "silky" appearance, all desirable characters of a wrapper leaf. In addition, there was a relatively low percentage of "darks", with the upper grades of bright color and "pink" veins.

On another field (XIII), with somewhat heavier soil, the effects of soybean oil meal from the expeller and solvent processes were compared with a fertilizer of standard composition.

From the expeller process a coarser material, pellets, and the regular meal were included in the test. Three single plots were furnished with these different materials as the only source of nitrogen. Two check plots received the general fertilizer. The field was planted to Havana Seed tobacco. Growth was unusually vigorous here with no apparent differences between plots receiving the oil meals. Tobacco on the check plots appeared to be somewhat shorter.

Yield and grading records are given in Table 6 where it is seen that the highest grade index was obtained by the regular soybean oil meal, expeller process. The coarser material and the meal from the solvent process showed a little lower grade index but results were identical and higher than the average for the check plots. All the tobacco, however, from the soybean oil meal plots was of excellent quality with good color, texture and veins. There were no significant differences between the yields produced by the ihree materials, but they were all somewhat higher than those on the check plots.

Table 6. Soybean Oil Meal Tests. Yield and Grading Records for 1936

\begin{tabular}{l|c|c|c|c}
\hline \multicolumn{1}{c|}{ Source of nitrogen } & \multicolumn{2}{|c|}{ Acre yield } & \multicolumn{2}{c}{ Grade index } \\
\cline { 2 - 3 } & Plot & Av. & Plot & Av. \\
\hline General fertilizer, Check 1 & 2483 & & .384 & \\
General fertilizer, Check 2 & 2386 & 2317 & .444 & .400 \\
*Cottonseed meal on Field V & 2082 & & .372 & \\
\hline Soybean oil meal (regular) plot on Field V & 2374 & & .441 & \\
Soybean oil meal (regular) on Field XII & 2490 & 2482 & .463 & .454 \\
Soybean oil meal (pellets) & 2559 & & .455 & \\
Soybean oil meal (solvent process) & 2505 & & .456 & \\
\hline \hline
\end{tabular}

* Average of three plots. 
Nitrification studies have revealed that soybean oil meal produces nitrate at a higher and more uniform rate than other organics, such as cottonseed meal. Furthermore, there is no appreciable difference in the rate of nitrification among the various kinds of soybean oil meal included in the test. There was thus no material gain in any respect obtained from applying the soybean product in pellet form. It may be mentioned also that the pellets have a tendency to segregate from the other ingredients in a fertilizer mixture.

As pointed out elsewhere in this bulletin (page 79), one single source of nitrogen appears to be as good, if not better than several combined. It seems important, therefore, to direct investigation toward finding the most suitable source for cigar leaf tobacco. So far, soybean oil mea has given exceptionally good results. Further research, however, is necessary to observe the effect of this material on different types of tobacco, under a wider range of conditions and on larger areas than the rather restricted experimental plots.

\section{Tests On Shade Tobacco}

The tests were also extended to shade tobacco in 1936 . In an eightacre tent, soybean oil meal was substituted for cottonseed meal on ten rows across the center of the field at the rate of one ton to the acre. In all other respects the two formulas were identical. Observations during the summer showed no striking differences in the growth of tobacco on the two formulas. At time of harvesting 50 hands, 2,000 leaves, were tagged from each priming for sorting records and an equal number on adjacent bents where the regular cottonseed meal formula was used. The cured tobacco was graded by experienced sorters in the warehouse of the Gershel-Kaffenburgh Tobacco Company. The results of the first three primings, nine leaves to the plant, are shown in Table 7 *

Table 7. Yield and Grading Records of Shade Tobacco Grown ox Soybean Orl Meal Foruula

\begin{tabular}{l|l|l|c|c}
\hline \multicolumn{1}{c|}{ Position of leaves on stalk } & \multicolumn{1}{c|}{ Meal used } & Acre yield & $\begin{array}{c}\text { Price } \\
\text { per pound }\end{array}$ \\
\hline 1st, 2nd, 3d & $\begin{array}{l}\text { Cottonseed } \\
\text { Soybean }\end{array}$ & $\begin{array}{c}105 \\
102\end{array}$ & $\begin{array}{c}\$ 1.806 \\
1.636\end{array}$ \\
\hline 4th, 5th, 6th & Cottonseed & 199 & 2.152 \\
\hline 7th, 8th, 9th & Soybean & 207 & 2.307 \\
\hline Total yield & Cottonseed & 257 & 1.915 \\
(First 9 leaves) & Soybean & 243 & 2.043 \\
\hline Weighed average price & Cottonseed & $\mathbf{5 6 1}$ & \\
\hline \hline
\end{tabular}

To compute the price per pound, after the leaves were sorted into the usual commercial grades, the weight of each was multiplied by the current price received by the packer for that particular grade, the products added, and the sum divided by the total number of pounds in the lot.

* The upper leaves had not yet been sorted when this was written. 
Observations of the tobacco at the time of sorting indicate that the soybean oil meal produced thinner and more elastic leaves than the cottonseed meal. Above the first picking the leaves from the soybean oil meal plot were "silky", while those from the cottonseed meal plot were somewhat rougher. These differences in texture resulted in a greater proportion of leaves in the more valuable grades, such as LL's, LC's, $\mathrm{LV}^{\prime}$ 's and $\mathrm{LV}_{2}$ 's, and fewer in the less desirable grades such as YL's, Y's and ML's.

The summarized results show that in this test there was no increase in weight from the use of soybean oil meal, but there was sufficient improvement in quality to net the dealer nine cents a pound above the tobacco grown on the cottonseed formula.

Other growers tried soybean oil meal this year on a part of their acreage and have reported favorable results. However, exact data on these tests are not available.

\section{SINGLE SOURCES VERSUS MIXED SOURCES OF NITROGEN IN THE FERTILIZER}

In the mixing of tobacco fertilizers, it is an almost universal custom to include more than one material to supply the required percentage of nitrogen. Ordinarily the most bulky nitrogenous ingredient is cottonseed meal. This is usually supplemented by smaller amounts of such materials as dry ground fish, castor pomace, linseed meal, urea, nitrate of soda, nitrate of potash, and others.

There are two reasons for this practice. In the first place, some of them supply nitrogen at a less cost per unit. The second and perhaps more important reason is that growers and fertilizer dealers believe that the different materials in a mixture supplement one another by decomposing at different rates. Thus a mixture supplies available nitrates in a more constant and presumably more favorable succession. The mineral nitrates are added on the theory that there may be a shortage of available nitrogen in the soil early in the season and that these added nitrates, which are immediately usable by the seedling plants, may serve to start growth more quickly. Hence they are popularly termed "starter nitrogen". Most fertilizer mixtures contain at least a small proportion of starter nitrogen. In the absence of any published tests to substantiate the correctness of these theories, a series of experiments was conducted on Broadleaf tobacco with the object of answering specifically these two questions: (1) Does a mixture of organic nitrogenous materials produce a better yield or higher quality than a single nitrogenous material? (2) Does the inclusion of starter nitrogen improve either the yield or grading?

The answers will be discussed separately although the plots from which the data were taken were intermingled on the same field of Broadleaf.

\section{Single Organics Versus Mixed Organics}

Five natural organic materials were used in these tests: Cottonseed meal, castor pomace, linseed meal, dry ground fish and corn gluten meal. The first four are the most commonly used organic materials in tobacco 
fertilizers. Corn gluten meal is not in common use but has been tried experimentally at the Station for several years with good results. Each of these was used alone as the only source of nitrogen in plots of Broadleaf, one twenty-fifth of an acre in area. On adjacent plots various combinations of the same meals, as indicated in Table 9, were used on duplicate plots: five of the single sources and twelve of combined sources. The actual quantity of nitrogen applied was the same in all cases, 200 pounds of nitrogen $(\mathrm{N})$ to the acre. The usual quantities of potash, phosphorus, magnesium and calcium were also included in the fertilizer and were equal on all plots. The field was fairly uniform and the plots well distributed to avoid possible favoring of any one treatment. The experiment was continued on the same plots for five years. All plots were set the same day and all cultural operations were uniform. Observations on the growing crops in the field did not show any consistent differences as between the various organics or the combinations of them.

All were weighed and sorted separately in the station sorting shop by commercial sorters. The records of yield and grading are shown in Tables 8 and 9.

Comparing the single sources, it will be noted that corn gluten meal gave the highest yield, while linseed meal had the best grading, a result that we have usually noted in other tests of these malerials. Comparing the combinations with the single sources it is seen that, with one exception, any single material produced a somewhat higher yield alone than when it was combined with other materials. With respect to the grade index, however, it is difficult to draw any conclusions except that the linseed combinations made a very good showing, but never as good as linseed alone. If we compare the average of all the single sources with the average of all the combined sources, we find that the single sources gave a little better yield, while the grade index was almost identical.

Our final conclusion from this five-year test is that, contrary to popular opinion, nothing is gained in yield or quality by combining sereral organics. A single organic material will give as good results. As a means of saving on the cost of the fertilizer, however, these tests indicate that less expensive materials may well be substituted for a part or even all of the more expensive ones. Thus the grower is always in a position to take advantage of fluctuating prices and to keep costs down.

\section{Nitrate Starter in the Mixture}

On the same field, on 11 plots adjacent to and intermingled with the above mentioned, we used the same combinations of organics as in the previous experiment but with a nitrate starter, nitrate of potash, supplying 40 pounds of nitrogen to the acre. The amount of the organic materials was reduced in proportion in order to keep the total quantity of nitrogen the same on all plots, 200 pounds to the acre. In all other respects the fertilizer was the same and the cultural operations were alike.

Careful observations every year failed to show that the plants started more rapidly on those plots to which the nitrate had been added. Neither was the growth in any way better. The sorting and grading results are shown in Tables 9 and 10 . 


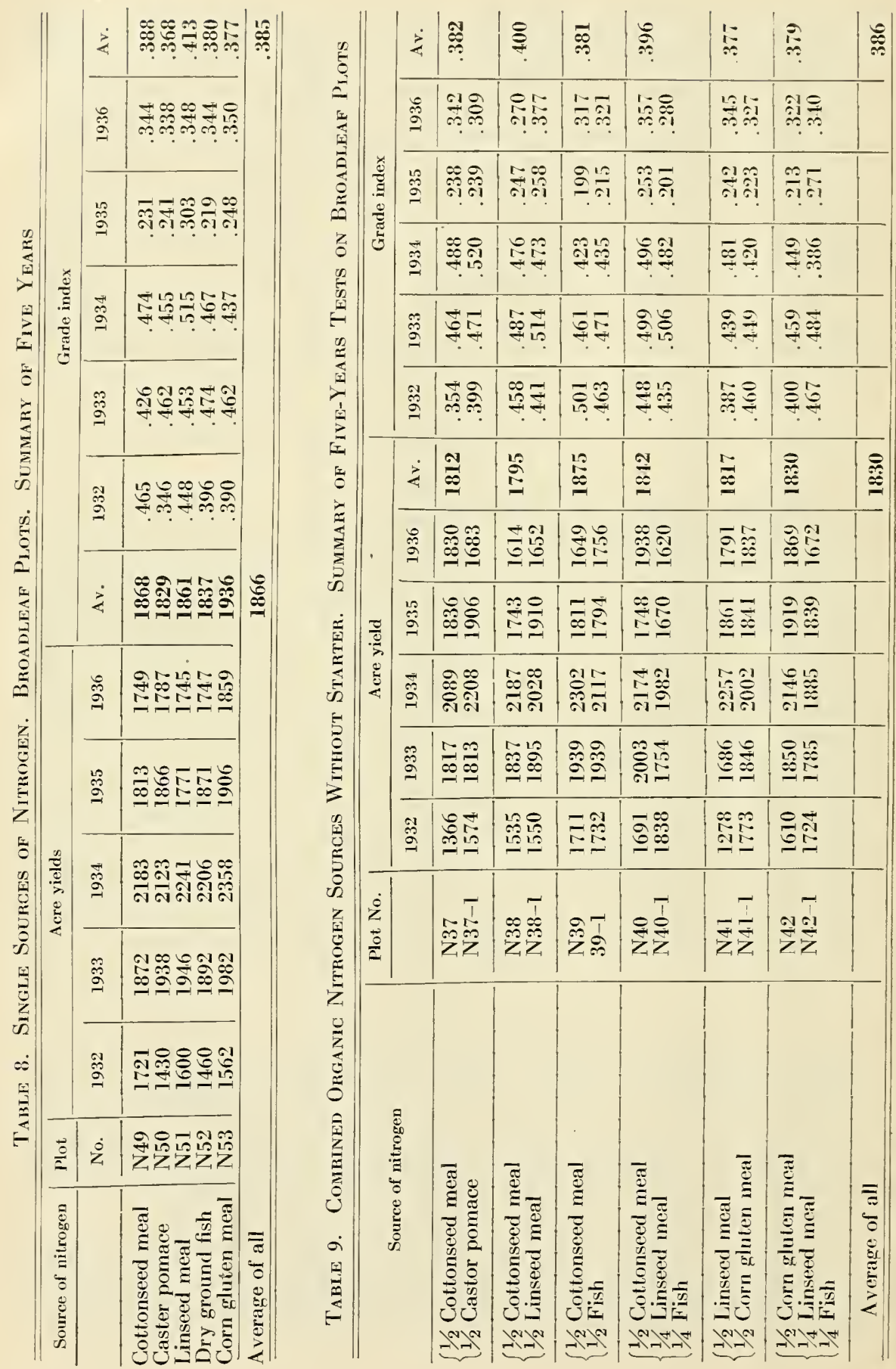




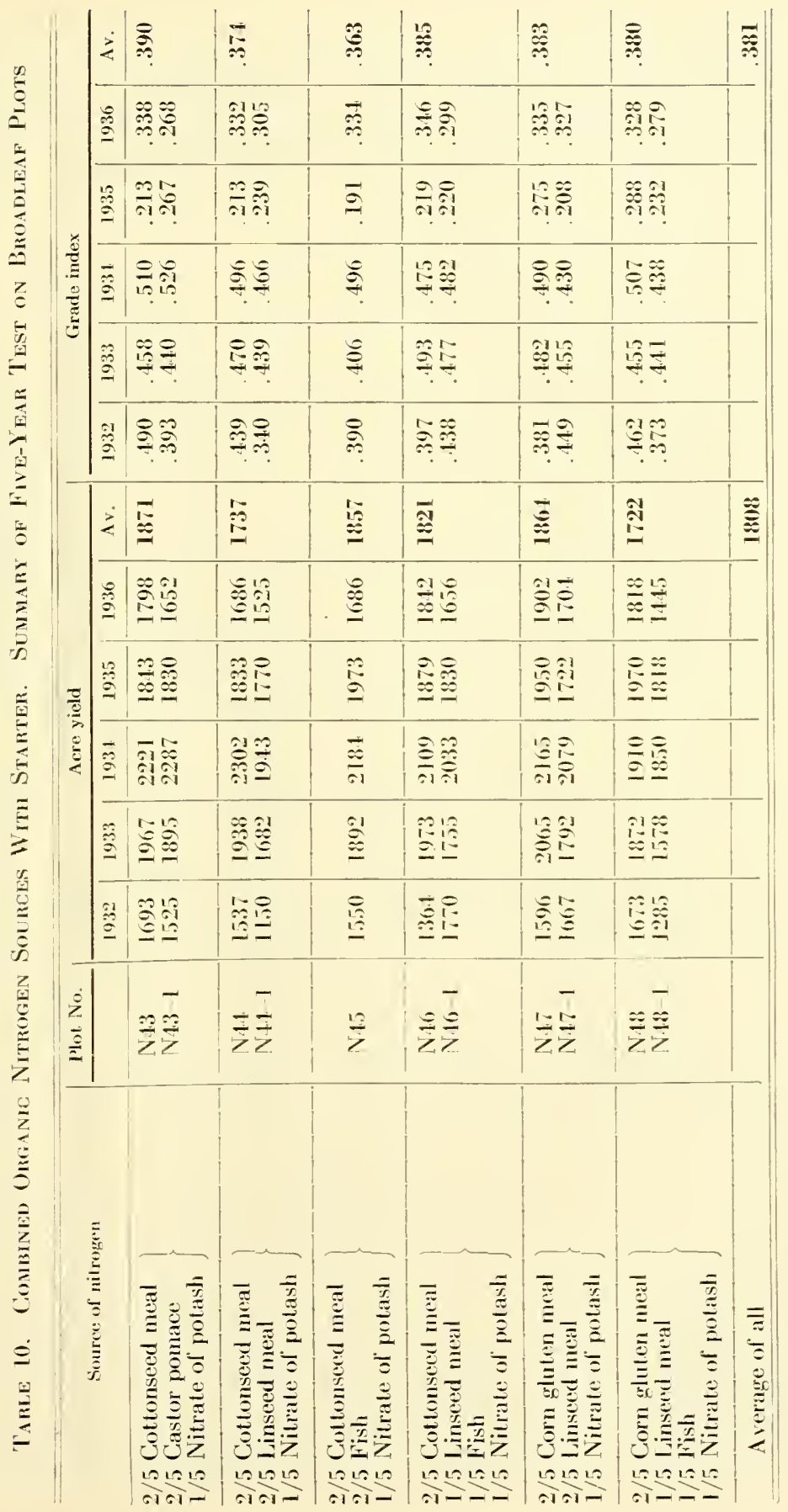


The results are not uniformly consistent, but comparing the average of all plots with starter and without starter, it will be seen that both the yield and grade index were somewhat better when no starter was used. At least we may conclude that there has been no advantage in adding the starter nitrogen. The explanation probably is that in ordinary practice, there is always a sufficient quantity of nitrate in the soil to fill the limited requirements of the small plants early in the season.

\section{FRACTIONAL APPLICATIONS OF NITRATE OF SODA}

It has been long known that plants most easily absorb nitrogen in the form of nitrates. To this rule tobacco is no exception. Nitrates evidently provide within the plant a more facile starting point in the metabolic function of nitrogen. It should, therefore, be of importance to provide a continuous supply of nitrates for the plants. This is carried out in a measure through the common practice of tobacco fertilization in the Connecticut Valley where cottonseed meal and other organics provide the essential part of the nitrogen. These organics contain very little nitrogen in the nitrate form, but the complex, nitrogenous materials in them are broken down gradually by the soil organisms and ultimately are supplied to the plant in simple nitrate form. Biological processes in the soil, then, are Nature's aid in supplying the nitrates during the season.

Weather conditions, however, vary considerably between extremes of hot and cold spells, drought and excessive rains, which all in various ways adversely affect a steady and uniform supply of nitrates.

Therefore, a logical procedure would be to apply the nitrogen to the growing crop in several fractions rather than in one dose before planting. Experiments along this line were carried out at this Station in 1926 through 1930. The greater part of the cottonseed meal and all of the nitrates included in the formula were reserved for two later applications. The results for the period, however, showed that such fractional applications were disadvantageous in a very dry season and beneficial in a rainy season. Since weather conditions are never known in advance, it was concluded that the best practice would be to apply all the fertilizer before planting, and additional nitrogen in case of excessive precipitation.

Another modification of the fractional application idea was suggested by the results of our experiments with nitrate of soda as the only source of nitrogen in the mixture. The latest published report on the tests with nitrate of soda (Conn. Agr. Exp. Sta. Bul. 386: 550-551) related briefly the results for the past ten years. For the first six years, with the nitrate applied all at one time before setting, the results were very unfavorable because the nitrogen was leached away in the early rains. For the following four years, with the nitrate divided into five applications, both yield and grading were vastly improved.

The five applications of nitrate of soda, each supplying 40 pounds of nitrogen per acre, were made at about 10-day intervals. The first one 
was made a few days before planting, together with all the other nutrients called for in the formula. The next was made a few days after planting, and the rest at 10-day intervals, unless heavy rains occurred in the period, in which case the nitrate of soda applications followed immediately. The last application was made within the first week of July. The type of soil on which this experiment was conducted was a very light, sandy loam of the Merrimac series.

From the work on soil nitrate production by single sources of nitrogen, reported by Street (Conn. Agr. Exp. Sta. Bul. 386: 563), it was shown that nitrate of soda, in fractional applications, provided a supply of nitrate at a rate about equal to that of any of the organics, possibly with the exception that the quantity of nitrate in the second week of June was unnecessarily high (more than 100 pounds per acre as compared with about 50 pounds for the organics). It is likely that the second application could be reduced to lialf, making the total 180 pounds N per acre, yet no indications have been observed that 200 pounds adversely affected the results.

The applications of nitrate of soda were completed at a time when the crops were less than half grown. It must be assumed, thms, that the plants were able to absorb a reserve of nitrates considerably greater than the prevailing physiological need, since leaching rains, especially in 1935, and irrigations occurring after the completion of the applications, caused no visible symptoms of starvation of the leaf during the now completed five-year period of this experiment.

The results from the present (1936) season show lhat nitrate of soda, with one exception, produced as high a yield, 2,250 pounds per acre, as any of the single sources tested. In grading (grade index .389) it excelled many of the common "meals".

In comparing the average results of the past five years with other single sources of nitrogen carried on for the same lenglh of time, nitrate of soda has produced the highest grade index (.410) with linseed ineal close behind (.403). The average yield, 1,812 pounds per acre, is somewhat lower than, for instance, that for cottonsecd meal, 1,90.1 pounds per acre.

Since the results from fractional applications of nitrate of soda are so obviously in line with those from the organics, the experiments suggest that the main, if not the sole adrantage of the "meals" is equalled by supplying the nitrates at a proper rate. Undoubtedly this explains why "meals" have so long had a prominent place in tobacco fertilization in the Connecticut Valley, where most of the tobacco land is of a sandy type with a mininum capacity to retain the nitrates at times of excessive rains.

Through the continuous use of nitrate of soda as a single source of nitrogen, the soil has become less acid. During a 10 -year period the pII values have increased from 5.2 to about 6.0 in early spring. This, however, is not due to an accumulation of sodium, as shown by our lysimeter data, since sodium is readily leached, leaving other raluable bases almost unaffected. 
Chemical analysis has shown that only a very small percentage of sodium is absorbed by the tobacco plant. Moreover, the absorption of potash has not been adversely affected.

Nitrate of soda, used alone, obviously does not replenish minor elements to as fine a degree as the "meals". Thus a merit might possibly be added to a material containing such elements as impurities.

The economical side of the problem is whether or not one could use nitrate of soda alone in place of other sources of nitrogen. The cost of nitrogen in this material is about half that of any of the common "meals", which permits a saving in the cost of fertilizer. This, however, must be balanced against the extra labor cost involved in the fractional applications, mainly hand labor. This whole idea should be tried out by some commercial grower on a larger area than is permissible with plot work at the station farm.

\title{
EXPERIMENTS ON CONTROL OF INSECTS OF TOBACCO, 1936
}

\author{
Austin W. Morrill, Jr.1 and Donald S. Lacroix ${ }^{2}$
}

Because of the increasing seriousness of some insect problems, particularly those presented by flea beetles, thrips, and wireworms, the Connecticut Valley tobacco growers asked for assistance from the United States Department of Agriculture to facilitate the development of adequate control methods. After an investigation of the situation, the Bureau of Entomology and Plant Quarantine of the United States Department of Agriculture assigned to this Station a full-time entomologist (Morrill) to coöperate with the station entomologist (Lacroix) who has been conducting insect control experiments during the summers at Windsor since 1930. This is a report of the coöperative experiments of the first summer, begimning on June 2, 1936.

\section{Flea Beetles}

The major problem attacked during this season was the control of the potato flea beetle, Epitrix cucumeris Harris, on shade and field tobacco. This beetle has been very destructive during the past few years. At the time the investigations started, it was extremely abundant in potato fields, whence it was believed to have migrated to tobacco, especially after the application of Bordeaux mixture to the potatoes. Duplicate control experiments were commenced in two shade tents about a mile apart.

${ }^{1}$ Junior Entomologist, Bureau of Entomology and Plant Quarantine, United States Department of Agriculture. Station.

${ }^{2}$ Assistant Entomologist of the Department of Entomology of the Connecticut Agricultural Experiment 


\section{Experimental Methods in Shade Tents}

Plots were laid out in these tents so that each consisted of 10 bents, or one-quarter acre. Since it was desired to obtain empirical knowledge rather than extremely precise results during this first season's work, the plots were not subdivided and randomized, according to present-day approved procedure, but were laid out parallel. All plots used in the experiments bordered on the outside of the tent.

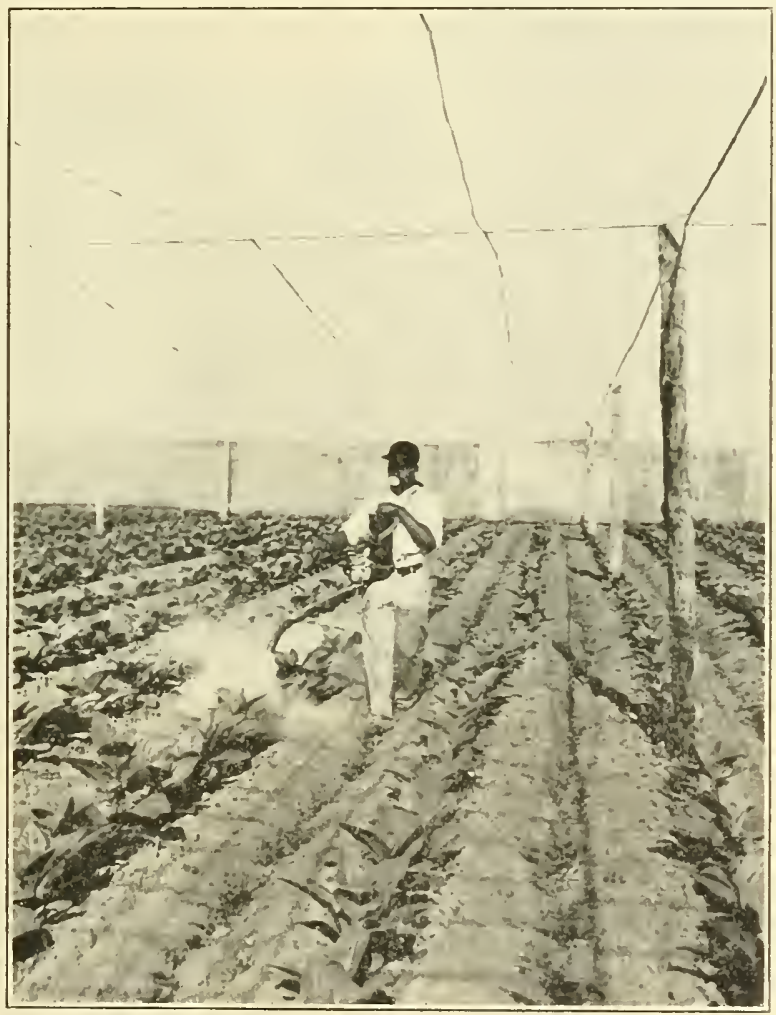

Figure 4. Dusting young plants of shade-grown tobacco for control of the potato flea beetle, Windsor, 1936. The operator is using a dust mask.

With one exception the insecticides used were diluted with sterile tobacco dust, finely ground and certified by the manufacturers to be a by-product in the manufacture of nicotine sulfate. In plot No. 3, however, the two materials used diluted each other. Plot No. 1 was dusted with a mixture composed of two parts of the tobacco dust by weight to eight parts of barium fluosilicate. Plot No. 2 received a mixture containing one 
part by weight of cubé root powder (4 percent rotenone) and three parts of the diluent. Plot No. 3 was dusted with a mixture of two parts by weight of cubé root powder (4 percent rotenone) to eight parts of barium fluosilicate, and plot No. 4 received sodium aluminum fluosilicate, eight parts to two by weight of the diluent. Plot No. 5 was left untreated as a check (Figure 5).

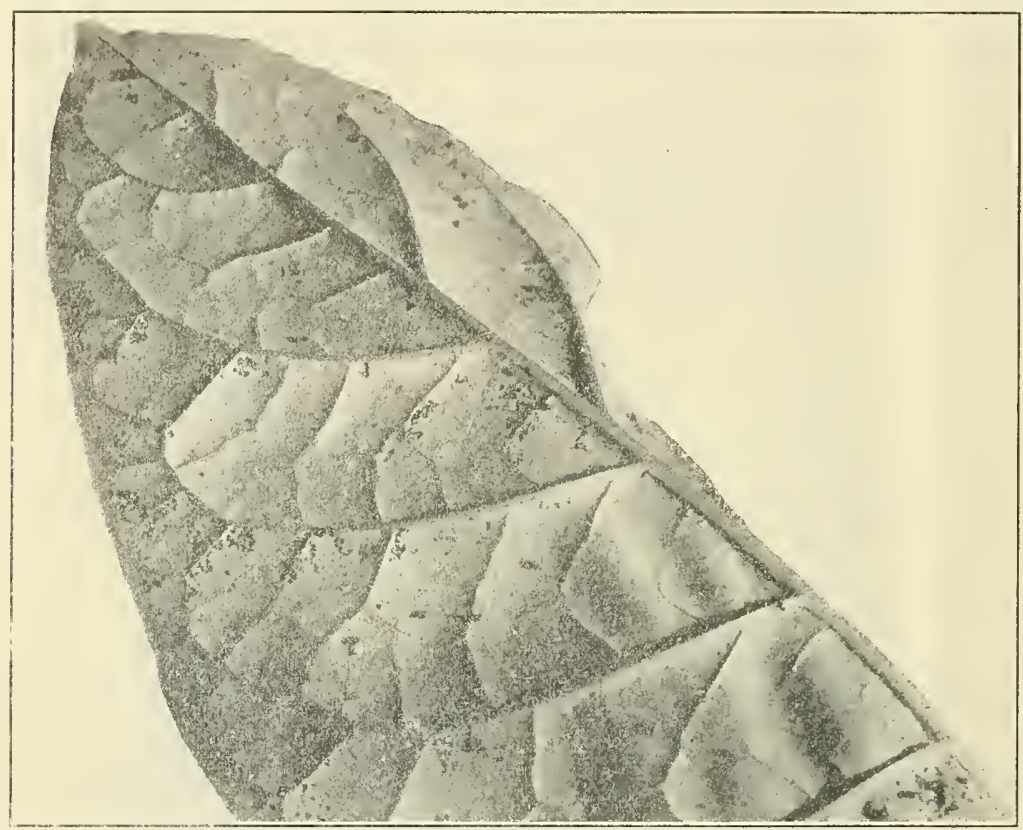

Figure 5. Tobacco leaf showing damage caused by the feeding of potato flea beetles.

Each plot was dusted once a week and insect counts were made before the dust application and also 48 hours after. These flea beetle poisons were applied in the early morning because the dew retained the dust on the leaves to better advantage and, what was more important, there was less air movement at that time. Dusting was nearly always completed before air currents had risen beyond the point of a Beaufort Scale No. 1, indicating wind movement of 0 to 3 miles per hour, or Weather Bureau "slight." Application was made by dusters of a type developed for use in the southern shade districts. These guns blew out the dust at a fairly even rate, with the exception of the sodium aluminum fluosilicate, which came out most unevenly. When the plants were small, all dusts were applied at the rate of four to six pounds to the acre and later six to eight pounds. The guns were pointed ahead of the operator and not directly at the plants. When the tobacco reached shoulder height, the gun nozzles were turned behind the operators and eight to ten pounds of dust per acre were applied, the dust being allowed to drift onto the plants by the "float" method. By turning the gun nozzles backward, a good fog of 
the material could be created without discomfort to the operators. However, the distribution of large quantities of dust under shade makes the wearing of respirators very advisable. It was also a protection for the operators to wear cloth aprons during the application (Figure 6).

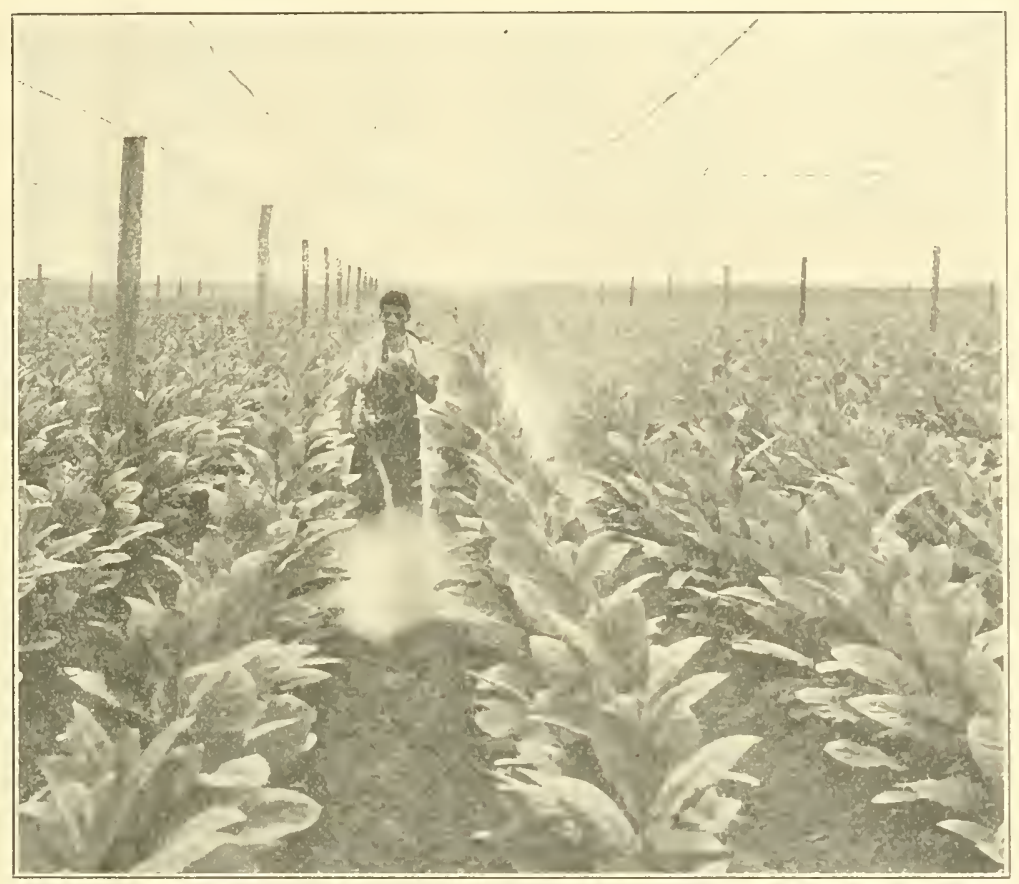

Figune 6. Dusting shade-grown tobacco plants for control of the potato flea beetle.

Four stations of 25 plants each were chosen at random in each plot and counts were made of dead and live beetles and of the apparent damage to the plants. At the time of picking, all leaves were primed from 100 plants selected at random in each plot in order to determine the amount of commercial damage.

\section{Summary of Experiments}

As will be seen from Table 11, each of the clust mixtures apparently controlled the flea beetles to about the same extent. Howerer, the factors of "painting" (white residue) of the leaf and danger of toxicity to the operator, which are not shown in this table, make the use of the mixtures of barium fluosilicate and tobacco dust, barium fluosilicate and cubé root powder, and sodium aluminum fluosilicate and tobacco dust, of uncertain desirability.

The results given in Table 11 represent only one season's work under the methods of experimentation outlined above. In these experiments 
Table 11. Mortality of Flea Beetles as a Result of the Application of

Insecticides on Experimental Plots of Shade Tobacco. Windsor, June, JuLY, August, 1936

\begin{tabular}{|c|c|c|c|c|c|c|}
\hline \multirow[b]{2}{*}{ Field } & \multirow[b]{2}{*}{ Plot $^{1}$} & \multicolumn{2}{|c|}{$\begin{array}{l}\text { Number of Insects } \\
\text { per } 100 \text { plants }\end{array}$} & \multicolumn{3}{|c|}{$\begin{array}{c}\text { Total commercial leaves injured } \\
\text { per } 100 \text { plants }\end{array}$} \\
\hline & & Dead & Alive & Slightly ${ }^{2}$ & Moderately ${ }^{3}$ & Severely 4 \\
\hline 1 & $\begin{array}{c}1 \\
2 \\
3 \\
4 \\
\text { Check }^{5}\end{array}$ & $\begin{array}{r}99 \\
136 \\
74 \\
59 \\
49\end{array}$ & $\begin{array}{r}334 \\
370 \\
207 \\
326 \\
2,333\end{array}$ & $\begin{array}{l}160 \\
183 \\
134 \\
171 \\
207\end{array}$ & $\begin{array}{l}161 \\
152 \\
114 \\
113 \\
232\end{array}$ & $\begin{array}{r}105 \\
61 \\
52 \\
53 \\
227\end{array}$ \\
\hline 2 & $\begin{array}{c}1 \\
2 \\
3 \\
4 \\
\text { Check }^{5}\end{array}$ & $\begin{array}{r}33 \\
75 \\
38 \\
37 \\
203\end{array}$ & $\begin{array}{r}94 \\
62 \\
48 \\
66 \\
399\end{array}$ & $\begin{array}{r}57 \\
35 \\
24 \\
49 \\
131\end{array}$ & $\begin{array}{l}70 \\
41 \\
28 \\
38 \\
90\end{array}$ & $\begin{array}{r}16 \\
25 \\
10 \\
2 \\
33\end{array}$ \\
\hline
\end{tabular}

1 Plots were treated with the following materials:

1. Barium fluosilicate, 8 pounds; tobacco dust, 2 pounds.

2. Cubé root powder (4 percent rotenone) 1 pound; tobacco dust, 3 pounds.

3. Barium fluosilicate, 8 pounds; cubé root powder (4 percent rotenone), 2 pounds.

4. Sodium aluminum fluosilicate, 8 pounds; tobacco dust, 2 pounds.

2 One quarter or less of leaf surface unfit for wrapper.

3 One complete side of midrib unfit for wrapper.

4 Both halves of leaf unfit for wrapper.

${ }^{5}$ Check plots were left completely untreated.

it will be noted that the mixture of cubé root powder and tobacco dust showed the highest number of dead beetles and the next to the least total leaf injury. The mixture of barium fluosilicate and cubé root powder was somewhat more effective if judged by the number of live beetles and the total leaf injury. This superiority is not believed to be sufficient to justify the increased cost of the mixture, since each material was used at nearly the same strength as when used alone. Barium fluosilicate and sodium aluminum fluosilicate seemed approximately of the same effectiveness and each caused considerable painting of the leaf. The sodium aluminum fluosilicate had the further disadvantage of coming unevenly from the gun and thus caused even heavier painting.

\section{Control Experiments on Havana Seed Tobacco}

During the seasons of 1935 and 1936 large quantities of a number of materials liave been applied on a commercial scale in efforts to control potato flea beetles on tobacco. Barium fluosilicate dust and various dust mixtures containing rotenone have in the past proved most effective and some growers have combined the two types of material. Where the two insecticides have been mixed together, half and half, and further diluted with tobacco dust, the control has been unsatisfactory. The reason for this is that each ingredient is diluted by the addition of the other and both are weakened by the further addition of tobacco dust.

In 1936 comparisons were made of the effectiveness of a dust mixture containing 1 percent of rotenone; barium fluosilicate diluted with tobacco dust one to three by volume; cubé root powder (1 percent rotenone) and barium fluosilicate mixed in equal parts with no tobacco dust; and a proprietary dust mixture containing .55 percent rotenone. These 
insecticides were applied to Havana Seed tobacco at the Experiment Station on July 18, July 27, and August 3, following the increase in the beetle population which began about July 15. Counts of flea beetles were taken at the time of dusting and again 48 hours later. Table 12 slows the data collected.

Table 12. Comparison of the Effectiveness of Dust Mixtures Applied for Flea Beetle Control on Havana Seed Tobacco. Wrndsor, 1936

\begin{tabular}{|c|c|c|c|c|c|c|}
\hline \multirow{2}{*}{ Insecticide used } & \multicolumn{6}{|c|}{ Flea beetle population on 25 plants } \\
\hline & July 18 & July 20 & July 27 & July 29 & Aug. 3 & Aug. 5 \\
\hline Dust mixture, $1 \%$ rotenone & 27 & 7 & 27 & 8 & 1 & 2 \\
\hline $\begin{array}{l}\text { Barium fluosilicate, tobacco } \\
\text { dust mixture, } 1 \text { to } 3\end{array}$ & 29 & 9 & 33 & - & ? & \\
\hline Dust mixture, $4 \%$ rotenone, & -7 & $y$ & 50 & ' & $=$ & 1 \\
\hline $\begin{array}{l}\text { barium fluosilicate, equal } \\
\text { parts }\end{array}$ & 18 & 5 & 17 & 5 & 3 & 4 \\
\hline Dust mixture, $.55 \%$ rotenone & 34 & 17 & 38 & 8 & 5 & 6 \\
\hline None (Check) & 24 & 125 & 27 & 52 & 31 & 33 \\
\hline
\end{tabular}

All dusts except one were applied at the rate of 12 pounds to the acre. The mixture of 1 percent rotenone dust and barium fluosilicate was applied at the rate of 15 pounds per acre. At the same time observations were made on the extent of flea beetle injury to the leaves on the various plots. The results are contained in Table 13.

Table 13. Flea Beetle Injury on Insecticide Test Plots (Number of Injured Leaves on 25 Plants) on Havana Seed Tobacco. Windsor, 1936

\begin{tabular}{|c|c|c|c|c|c|c|}
\hline \multirow[t]{2}{*}{ Date } & \multirow{2}{*}{$\begin{array}{l}\text { Degree of } \\
\text { injury }\end{array}$} & \multicolumn{4}{|c|}{ Number of leaves injurcd on plots treated with ${ }^{1}$} & \multirow{2}{*}{ Check } \\
\hline & & Material A & Material B & MateriaI C & Material D & \\
\hline \multirow{4}{*}{ July 18} & Slight2 & 2 & 5 & 4 & 2 & 3 \\
\hline & Moderate 3 . & 2 & 2 & 3 & 2 & 4 \\
\hline & Severet & 0 & l & 1 & I & 1 \\
\hline & Slight & 11 & 5 & 6 & 8 & 5 \\
\hline \multirow{3}{*}{ July 20} & Moderate & 2 & 3 & 2 & 4 & 11 \\
\hline & Severe & 0 & 0 & 0 & 2 & 14 \\
\hline & Slight & 5 & 7 & 6 & $1 \overline{1}$ & 12 \\
\hline \multirow[t]{3}{*}{ July 27} & Moderate & 3 & 5 & 5 & 2 & 7 \\
\hline & Severe & 1 & 3 & 1 & 1 & 3 \\
\hline & Slight & 10 & 9 & 11 & 11 & 15 \\
\hline \multirow{3}{*}{ July 29} & Moderate & 6 & 2 & 3 & 4 & 21 \\
\hline & Severe & 2 & 2 & 0 & 1 & 6 \\
\hline & Slight & $1 \overline{2}$ & $1 \overline{3}$ & 9 & 16 & 18 \\
\hline \multirow[t]{3}{*}{ Aug. 3} & Moderate & 5 & 10 & 6 & 9 & 25 \\
\hline & Severe & 1 & 2 & 0 & 1 & 18 \\
\hline & Slight & 12 & 13 & 11 & $1 \%$ & 21 \\
\hline \multirow{2}{*}{ Aug. 5} & Moderate & 6 & 12 & 7 & 11 & 32 \\
\hline & Severe & 1 & 3 & $i$ & 2 & 21 \\
\hline
\end{tabular}

1 Materials used:

A. 1 percent rotenone dust.

B. Barium fluosilicate, tobacco dust, 1 to 3 .

C. 1 percent rotenone dust, barium fluosilicate, equal parts.

D. .55 percent rotenone dust.

${ }^{2}$ One-fourth or less of leaf area unfit for wrapper.

s One-half of leaf unfit for wrapper.

4 Both halves of leaf unfit for wrapper. 
The figures in tables 12 and 13 indicate very little difference in the effectiveness of these materials, but all show a distinct improvement over the untreated check.

Dust residue on the leaves was not objectionable except on the plot treated with the mixture of barium fluosilicate and 1 percent rotenone dust, where there remained considerable white powder.

\section{Flea Beetle Resistant Tobacco}

In the Tobacco Substation Report for 1935 there appeared a discussion of some preliminary observations on the resistance of one type of tobacco to flea beetle attack. Population counts were made again this year on several fields to determine the extent of this apparent resistance. In every case the types known as No. 211 and shade-strain D were comparatively free from injury and from beetles.

The population counts were made by observing the number of beetles on 25 plants in each of four quarters of the field, making a total of 100 plants counted in each type. Two such observations were made on the Experiment Station tobacco and are tabulated in Table 14.

Table 14. Flea Beetle Population on Different Tobacco Strains. Experinent Station, Windosor

\begin{tabular}{lcc}
\hline & & \multicolumn{2}{c}{ Total number beetles per 100 plants } \\
\cline { 2 - 3 } Strain & July 17 & July 27 \\
\hline No. 211 & 45 & 34 \\
Other Havana & 95 & 199 \\
\hline \hline
\end{tabular}

The other fields were examined on July 31 with the results indicated in Table 15.

Table 15. Flea Beetle Population on Different Tobacco Strains on Commercially Grown Havana Seed and Shade Type Tobacco

\begin{tabular}{clc}
\hline Plot & Strain & Number beetles per 100 plants \\
\hline Field A & No. 211 & 29 \\
& Other Havana & 189 \\
\hline Field B & No. 211 & 2 \\
& Other Havana & 34 \\
\hline \multirow{2}{*}{ Field C } & Strain D & 4 \\
& Regular Shade & 27 \\
& Regular Shade & 30 \\
\hline \hline
\end{tabular}

Another interesting observation in this comnection was made on the station plots near some early potatoes. When the potato crop was harvested, the flea beetles migrated to the adjacent tobacco plants (211 strain). As many as 50 beetles could be found on a single leaf, and they remained there for about 15 hours before a dust was applied. During the time between the infestation of the tobacco and the dusting, however, there was no appreciable feeding by the insects.

These facts and the results in 1935 indicate that the shade D and No. 211 strains are somewhat resistant to flea beetle attack. 


\section{Dispersal of Flea Beetles}

It is a common belief of growers that the beetles migrate from potato fields into the tobacco fields. In order to discover whether this is true and to determine the extent and time of such migration, screens covered with adhesive material were erected, and the number of beetles caught was counted every second day. The screens were made of fine mesh wire screening, and an area one foot wide by eight feet high was coated with sticky material on each side. Twelve of these were then placed in three rows of four screens each: one row between a potato field and a field of sun tobacco; one between the potato field and a shade tent; and one between the shade tent and a field of Havana Seed tobacco. All three fields were contiguous. The counts were recorded not only with respect to the side of the screen on which the beetles were found, but also as to the number of feet above the ground.

Table 16. Flea Beetles Caught on Screens Covered with Sticky Adhesive Material. East Granby, Connecticut, June-August, 1936

\begin{tabular}{|c|c|c|c|c|c|c|}
\hline \multirow{3}{*}{ Date } & \multicolumn{3}{|c|}{ Front } & \multicolumn{3}{|c|}{ Back } \\
\hline & \multicolumn{3}{|c|}{ Average number beetles per sereen } & \multicolumn{3}{|c|}{ Average number beetles per sereen } \\
\hline & Group 1 & Group 2 & Group 3 & Group 1 & Group 2 & Group 3 \\
\hline $\begin{array}{cc}1936 \\
\text { June } & 15 \\
\text { “. } & 17 \\
\text { “. } & 19 \\
\text { “. } & 21 \\
\text { ". } & 23 \\
\text { “" } & 27 \\
\text { “. } & 29\end{array}$ & $\begin{array}{r}32 \\
12 \\
3 \\
16 \\
16 \\
7 \\
31 \\
9\end{array}$ & $\begin{array}{r}16 \\
8 \\
2 \\
11 \\
8 \\
1 \div \\
1 \frac{7}{6}\end{array}$ & $\begin{array}{l}12 \\
17 \\
10 \\
12 \\
30 \\
23 \\
11 \\
11\end{array}$ & $\begin{array}{r}46 \\
23 \\
5 \\
15 \\
5 \\
5 \\
12 \\
3\end{array}$ & $\begin{array}{r}11 \\
7 \\
\frac{1}{10} \\
6 \\
5 \\
26 \\
4\end{array}$ & $\begin{array}{r}33 \\
20 \\
9 \\
52 \\
29 \\
19 \\
78 \\
18\end{array}$ \\
\hline July 1 & 7 & 3 & 4 & 1 & 2 & 2 \\
\hline “ 3 & 9 & 8 & 17 & 2 & 6 & 19 \\
\hline “ 5 & 4 & 3 & 3 & $\overrightarrow{1}$ & 1 & 7 \\
\hline .7 & 8 & 12 & 15 & 2 & 2 & $\tilde{5}$ \\
\hline$\because \quad 9$ & 5 & 7 & 7 & 2 & 7 & 7 \\
\hline “ 11 & $\tau$ & $\div$ & 7 & 2 & 1 & 7 \\
\hline * 13 & 3 & 3 & 8 & 3 & 3 & $\div$ \\
\hline . 15 & 3 & $\overline{7}$ & 29 & 2 & 8 & 9 \\
\hline " 17 & 17 & 26 & 110 & 2 & 2 & 36 \\
\hline “ 19 & 7 & 9 & 11 & 6 & 4 & 17 \\
\hline “" 21 & 21 & 13 & 108 & 5 & 5 & 20 \\
\hline “ 23 & 23 & 46 & 128 & 27 & 17 & 54 \\
\hline “. 25 & 17 & 20 & 38 & 25 & 7 & 22 \\
\hline " 27 & 9 & 15 & 23 & 16 & 15 & 36 \\
\hline “ $\quad 29$ & 31 & 81 & 109 & 22 & 34 & 104 \\
\hline “ 31 & 20 & 46 & 51 & 11 & 10 & 53 \\
\hline Aug. 1 & 25 & 42 & 57 & 8 & 12 & 14 \\
\hline & 15 & 62 & 124 & 11 & 14 & 40 \\
\hline " & 12 & 32 & 49 & 10 & 9 & 28 \\
\hline ، $\quad 9$ & 32 & 26 & 33 & 14 & 4 & 10 \\
\hline ،. 11 & $1 \overline{1}$ & 10 & 2 & 9 & 9 & 15 \\
\hline .. 13 & 11 & 1 & 17 & 6 & 6 & 5 \\
\hline " 15 & 19 & 17 & 37 & 4 & 11 & Ј \\
\hline .17 & 4 & 12 & 15 & 10 & 8 & 8 \\
\hline " 19 & 8 & 11 & 11 & 5 & 6 & 3 \\
\hline ، 621 & 9 & 5 & 9 & 1 & 3 & 1 \\
\hline ، 25 & 5 & 9 & 8 & 1 & 2 & 2 \\
\hline " 27 & 8 & 1 & 3 & 2 & 3 & 2 \\
\hline . 31 & 3 & 3 & 7 & 1 & 1 & 3 \\
\hline
\end{tabular}


The potatoes were sprayed with Bordeaux mixture only once, following which there was a slight increase of beetles observed on the screens. The number of beetles caught, of course, represents only a segment of the air one foot in width, or a coverage by the four screens in each group of about one foot in 40. The large numbers of beetles on the potato plants were therefore represented by comparatively small numbers on the screens. Consistent dusting of the shade tobacco at six-day intervals may have somewhat affected the differential between the catches made on the outward and inward faces of the screen. Nevertheless, as will be seen by the following table, the beetles seemed definitely to fly from the potatoes to the Havana Seed tobacco and to the shade tent and showed a marked preference for the latter. The catches made on the screens also indicated two broods, which coincided in date with the period of greatest abundance on the check plots in the dusting experiments.

\section{Flea Beetle Emergence Studies}

After the first emergence (spring brood) of flea beetles had subsided and before the second generation had made an appearance, large cloth cages were placed over 12 plants, 6 in the open field and 6 in a shade tent. These plants were observed to have been attacked by the earliest emerging flea beetles but were otherwise typical. The cages were examined after being placed to make sure that no flea beetles were inside at that time. They were then checked every second day and the number of flea beetles emerged was noted. The results of this study were negative, since comparatively few individuals emerged in the cages, although the soil around the caged plants was of approximately the same moisture content as the general field.

The numbers of beetles found in the untreated checks of the toxicity experiments, which surrounded the cages, could not have been accounted for by such emergence. General observations indicated that beetles were entering the tents in large numbers from the outside. However, the beetles showed definite preference for certain plants, often the diseased or otherwise weakened ones, and many plants were not attacked at all until a heavy infestation was observed on other plants nearby. For this reason, it is possible that the tobacco chosen was not representative of the infested plants. Since these heavily infested plants were often some distance within the shade tent, it would seem to indicate that some breeding was occurring within the field.

The flea beetles appeared in the fields in large numbers about the middle of June, but the summer brood was very slow in emergence, the peak occurring suddenly around July 23 and continuing through the first week in August. Usually there is a gradual but decided increase from about July 4 on, but this year there was little or no "build-up" preceding the peak. But little rain fell until July 20, when there was .46 inch. On July 23 there was a rainfall of 1.24 inches. Careful and continuous dusting on the part of most growers of shade tobacco reduced the infestation greatly. Havana Seed tobacco had light to moderate infestations and Broadleaf in some sections was comparatively free from injury. 


\section{Observations on Large-Scale Dusting}

Nearly all growers of shade tobacco dusted regularly at about 6-day intervals with dusts containing .67 to .83 percent rotenone, and these treatments apparently prevented the flea beetle from doing any considerable damage. It was also impossible to determine what the potential damage might have been, as has been stated, but in some instances where growers did not dust regularly, or thoroughly, as in the case of the untreated checks in the experiment, a larger amount of damage was noted. Growers were generally of the opinion that the dusting was of considerable benefit. The results of counts of flea beetles in a field dusted by a grower in the manner mentioned above are given in Table 17.

Table 17. Total Counts from Four Stations of 25 Plants, Each in a Field Dusted by Grower with Proprietary Rotenone Dust.

Windosor, Connecticut, $1936^{1}$

\begin{tabular}{|c|c|c|c|c|c|}
\hline \multirow{2}{*}{$\begin{array}{l}\text { Count for } \\
\text { week ending }\end{array}$} & \multicolumn{2}{|c|}{ Flea beetles } & \multicolumn{3}{|c|}{ Plants injured (number leaves) } \\
\hline & Alive & Dead & Slightly ${ }^{2}$ & Moderately ${ }^{3}$ & Severely ${ }^{4}$ \\
\hline July 3 & 9 & 4 & 24 & 19 & 2 \\
\hline " 10 & 1 & 1 & 19 & 13 & 3 \\
\hline “ 17 & 19 & 5 & 13 & 9 & 5 \\
\hline “ 27 & 7 & 7 & 5 & 3 & 3 \\
\hline Aug. 1 & 0 & 6 & 3 & 0 & 0 \\
\hline
\end{tabular}

1 Dust applied at about 6-day intervals, 8 lbs. per acre. Dust contaned .83 percent rotenone.

2 One-fourth or less of leaf area unfit for wrapper.

3 One-half of leaf unfit for wrapper.

Both halves of leaf unfit for wrapper.

\section{Other Crops as Counter Attractions for Beetles}

Flea beetles were observed feeding on corn planted in rows between potatoes and field tobacco, one grower reporting that the corn had been intended as a "buffer." That not all the beetles stopped at the corn, however, was shown by the comparatively heavier infestation of the first four to five rows of the tobacco on that side. Sunflowers, on the other hand, which were planted by one grower for shade in alternate rows with his Havana Seed tobacco, proved definitely attractive to the flea beetles. These sunflowers were riddled by the beetles while the tobacco showed little or no damage, nor were many beetles found resting on the tobacco although the sunflower leaves were heavily populated.

\section{The Use of Power Dusters for Control of Flea Beetles}

During the summer of 1936 , the use of power machinery was undertaken for the application of poison dusts for flea beetle control. Two types of dusters were used by some of the larger growers on shade tobacco, one a horse-drawn machine and the other tractor-drawn. 
The accompanying photograph (Figure 7) shows one of these types. Dust applied by these machines is distributed very evenly over the plants on both surfaces of the leaves because it comes out of the blower at a high velocity and also because of the swirling motion as it leaves the machine. The efficiency of the power duster further proved itself by greatly reducing flea beetle injury and by the ability of the duster to cover a large acreage in a short time. Several growers found it of use in dusting the outer, more severely infested bents after the tobacco growth prevented dusting the entire shade.

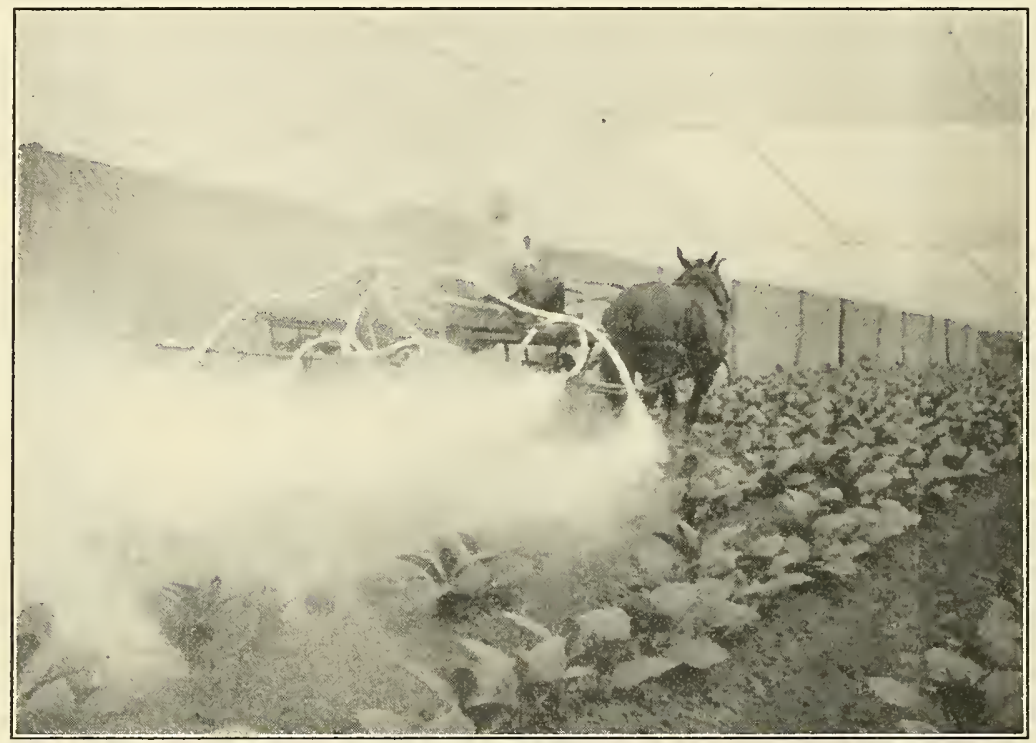

Figure 7. Power duster adapted for use in 1936 by tobacco growers in the Connecticut Valley for control of the flea beetle.

One drawback which will be remedied before another season is the height of the power duster. As a result of a conference with the manufacturer of the machine used in 1936, it is planned to increase the height so that dusting may be carried on until the tobacco reaches a maximum of four feet, six inches. (See Figure 7.)

\section{Thrips Control}

Experiments were conducted this season also on the control of tobacco thrips, Frankliniella fusca Hinds, with the same materials at the same dilutions as those which have been used experimentally in the Florida shade tobacco district. Duplicate plots were laid out in two separate shade tents, each plot being 2 bents, or .05 acre. Counts were made on 10 plants chosen at random in each plot. Applications were made at weekly intervals. 
The following materials were used, and these were sprayed on plots numbered in the order listed, at the rate of 2.5 gallons per plot and, in the last application, 5 gallons per plot:

1. Lauryl thiocyanate (1-400)

2. Nicotine sulfate, 40 percent strength (1-400)

Spreader (an oxidized, sulphonated petroleum product) (1-200)

3. Nicotine sulfate, 40 percent strength (1-400)

Molasses, black strap (1-20)

4. Pyrethrum extract (1-400)

Neutral liquid soap (1-250)

5. Cubé root powder, 4 percent rotenone ( 3 pounds to 50 gallons)

Spreader, (1-400) sulfated phenyl phenol

6. Cubé root powder (6 pounds to 50 gallons)

Spreader, (1-400) sulfated phenyl phenol

Plot No. 7 was left untreated as a check and plot No. 5 was later changed to cubé root powder, 12 pounds to 50 gallons of water.



Figure 8 Spraying experiments for control of the tobacco thrips.

As will be seen from Table 18, none of the materials tested proved satisfactory at the strengths used, although No. 3, containing molasses, seemed more satisfactory than the rest. The dosage on plot No. 5 was increased on July 10, when the plants were about half-grown, to 12 pounds of cubé root powder to 50 gallons of water. As may be seen from the table, this strength of cubé root powder may have had good results, although the greater dilution did not. The sudden and rapid growth of the plants after July 20 prevented further testing after that date. 
Table 18. Number of Live Insects Found and Number of Plants Affected per 10 Plants in Plots Sprayed with Various Mixtures for the

Control of the ToBacco Thrips, 1936

\begin{tabular}{|c|c|c|c|c|c|c|c|c|c|c|c|c|c|c|c|c|}
\hline \multirow[b]{3}{*}{ Date } & \multicolumn{8}{|c|}{ Number live thrips } & \multicolumn{8}{|c|}{ Number plants affected } \\
\hline & \multicolumn{5}{|c|}{ Plots No. } & \multirow{2}{*}{\multicolumn{3}{|c|}{$\begin{array}{cr}\mathrm{Ck} & \mathrm{Ck} \\
\mathrm{N} & \mathrm{S}\end{array}$}} & \multicolumn{5}{|c|}{ Plots No. } & \multicolumn{3}{|c|}{$\mathrm{Ck} \quad \mathrm{Cl}$} \\
\hline & 1 & 2 & 3 & 4 & 5 & & & & 1 & 2 & 3 & 4 & 5 & 6 & $N$ & $\mathrm{~s}$ \\
\hline \multicolumn{17}{|c|}{ East Granby } \\
\hline June 16 & 0 & 6 & 1 & 3 & 1 & 3 & 1 & 3 & 0 & $4 \mid$ & 1 & 6 & 1 & 3 & 1 & 3 \\
\hline " 23 & 7 & 6. & 1 & 3 & 1 & 2 & 4 & 3 & 3 & 4. & 1 & 3 & 1 & 2 & 3 & 2 \\
\hline July 1 & 1 & 0 & 3 & 1 & 3 & 5 & 0 & 4 & 1 & 0 & 3 & 1 & 3 & 5 & 0 & 4 \\
\hline $\begin{array}{ll}8 \\
4\end{array}$ & 29 & 31 & 19 & 27 & 21 & 30 & 28 & 35 & 5 & 8 & 7 & 7 & 8 & 10 & 8 & 10 \\
\hline " 10 & 1 & 19 & 22 & 1i & 15 & 22 & 17 & 0 & 1 & 8 & 7 & 8 & 10 & 7 & 9 & 0 \\
\hline “ $15^{1}$ & 4 & 8 & 5 & 17 & 5 & 18 & 14 & 15 & 4 & 6 & 4 & 8 & 3 & 8 & 7 & 7 \\
\hline “ 17 & 3 & 6 & 1 & 3 & 8 & 5 & 4 & 7 & 2 & 5 & 1 & 3 & 5 & 5 & 3 & 4 \\
\hline Total & 45 & 76 & 52 & 65 & 54 & 85 & 68 & 67 & 16 & 35 & 24 & 36 & 31 & 40 & 31 & 30 \\
\hline
\end{tabular}

\begin{tabular}{|c|c|c|c|c|c|c|c|c|c|c|c|c|c|c|c|c|}
\hline July 6 & 36 & 48 & 31 & $5 \mathrm{II}$ & 35 & 52 & 39 & 59 & 91 & 9 & 10 & 10 & 9 & 9 & 10 & $\overline{10}$ \\
\hline$\therefore 13$ & 43 & 66 & 15 & 31 & 30 & 65 & 40 & 123 & 9 & 9 & 9 & 9 & 9 & 9. & 9 & 10 \\
\hline “ 15 & 36 & 34 & 10 & 31 & 32 & 37 & 16 & 89 & 10 & 8 & 6. & 9 & 9 & 10 & 7 & 10 \\
\hline 《 $20^{2}$ & 7 & 21 & 13 & 32 & 8 & 31 & 7 & 48 & 4 & 9 & 6 & 10 & 7. & 9 & 7 & 10 \\
\hline Total & 122 & 169 & 69 & 145 & 105 & 185 & 102 & 314 & 32 & 35 & 31 & 38 & 34 & 37 & 33 & 40 \\
\hline
\end{tabular}

\footnotetext{
1 Dosage in plot No. 5 was changed on July 13 to cubé root powder 12 lbs. to 50 gallons of water.

${ }^{2}$ Rains prevented counting on July 23 , or spraying on July 27 . The plants were subsequently too well grown for effective spraying.
}

Several growers have stated that they were of the opinion that the dusting with proprietary cubé root powders, when the plants were wet with dew, had a controlling effect on the thrips population. They described the thrips infestation as potentially the worst in several years, but actual damage as being smaller than it has been at times in the past. The sprays were applied at the rate of 50 gallons per acre, equalling a dust of three to six pounds per acre. Since the dust is applied at the rate of eight pounds per acre, a heavy dew might form a toxic mixture, as in the case with the flea beetle. This heavier dosage is said to have been reported from Australia as effective and will be tested next season.

\section{Abundance of Various Species of Insects on Tobacco}

In 1936 the eastern field wireworm (Pheletes ectypus Say) probably caused less injury than for several years. In a few isolated cases damage was quite persistent, feeding being observed until late in June on one plantation. On some shade plantings in East Hartford, the larvae of this insect have been observed to infest tobacco on the lighter soils over a period of years. One grower noticed heavier infestation of plants set in the post rows and thought that this was due to the fact that more water is used in hand-setting of plants in these rows than is used in machinesetting in the others. 
Life history studies on this insect are also being continued. During the first year of larval life there is a gradual increase in size, and during the first few months of the second year, there occurs a sudden increase in length. Also, there is a wide variation in the rate of growth of individuals.

Larvae which hatched in June, 1935, ranged from 4 to $8 \mathrm{~mm}$. (one-sixth to one-third inch) in length on April 23, 1936. In July, 1936, these had increased in size from 6 to $14 \mathrm{~mm}$. (one-fourth to one-half inch) in length.

The red-legged grasshopper (Melanoplus femur-rubrum DeG) and the lesser migratory locust ( $M$. mexicanus mexicanus Saussure) were very numerous around East Hartford on Broadleaf tobacco and were found in large numbers in many shade tents in the western part of the Connecticut Valley, particularly in shades which had been in hay or weeds the previous year. The Carolina grasshopper (Dissotiera carolina Linn.) accompanied the above-mentioned species particularly on sun-grown tobacco.

Cutworms of various species were abundant and infestations of the dark-sided cutworm (Euxoa messoria Harr.) continued until early July on fields not protected with the usual poisoned bait. No serious infestations of the spotted cutworm (Agrotis c-nigrum Linn.) were noted although two specimens were taken in East Granby high up on shade-grown tobacco plants.

The tobacco budworm (Heliothis virescens Fabr.) was found but once and that early in July on Havana Seed tobacco in West Suffield.

The tobacco thrips (Frankliniella fusca Hinds) caused fairly severe injury throughout shade-grown tobacco areas this year, moderate to severe injury on Havana Seed tobacco, and slight injury to Broadleaf. The insect was taken in the field from late June through to early September when it was found on small suckers left after harvest in fields of Havana Seed tobacco.

Very few infestations of the common stalk borer (Papaipema nitela Guenee) were reported.

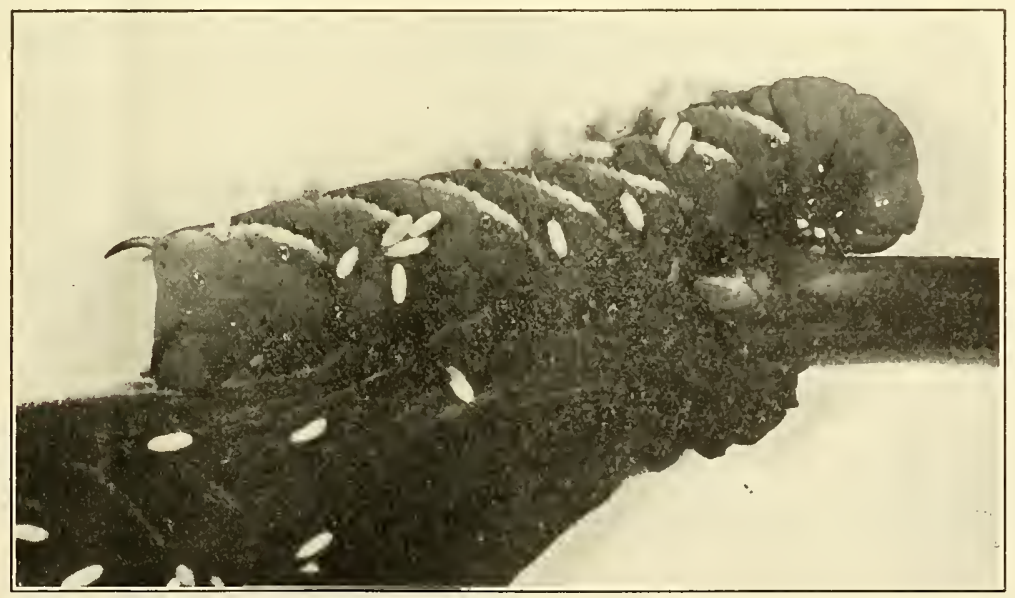

Figure 9. Larva of the tobacco hornworm (southern species) Phlegethontius quinquemaculata Haw., showing cocoons of the parasite, Apanteles spp. 
Hornworms (Phlegethontius quinquemaculata Haw. and $P$. sexta Johan.) were much less in evidence than in previous years throughout the Connecticut Valley, many fields being practically free from hornworm injury. Fields in Manchester which had been heavily infested two years ago had very few of these insects this year. Late in the season, however, many hornworms were taken from suckers throughout the tobacco districts in the Connecticut Valley. During the growing season about 80 percent of the individuals collected were parasitized by a small wasp (Apanteles spp.) and many were observed in tobacco-curing barns, studded with the small white cocoons of this parasite (Figure 9). Of the later generation, however, very little parasitism was noted and it is possible that many of these late individuals were able to complete development and enter the ground for pupation and hibernation before the severe cold killed the host suckers. In fields where many hornworms are noted, or where they have been a pest during the growing season, a second harrowing for the destruction of suckers might prove of sufficient benefit to warrant such treatment.

\section{STUDIES ON THE ANATOMY OF THE TOBACCO LEAF}

\section{THE MIDRIB}

\section{P. J. Anderson}

In contrast with the great wealth of information published on chemical and physiological investigations of the tobacco leaf, very few articles have appeared dealing with the anatomy, or structure, of the leaf. Yet it is quite probable that the structure may be just as important as chemical composition in its influence on the various factors that make up quality in tobacco. Many of the cultural operations, such as topping, suckering, irrigation and shading, change the leaf structure profoundly. Such anatomical alterations, in turn, make the leaves more suitable or less suitable for cigar wrappers and binders, or may change the combustion properties of the cigar.

Preliminary to a study of the effects of changes in cultural and environmental conditions on the leaf structure, it is necessary to investigate to the smallest detail the anatomy of the normal leaf in ordinary surroundings. Then we have a starting point from which we may study the changes that are effected by any modification of cultural practices or environment. A thorough knowledge of the normal anatomy is also a preliminary requirement to the study of all sorts of diseases and disorders of the leaves. Again it is prerequisite to the study of changes caused by parasitic organisms, viruses and insects.

It was with the object of acquiring such fundamental information that the present investigation was undertaken. The writer began this study in 1931-32 while on sabbatical leave and working in the Botanical Laboratory of the University of Heidelberg in Germany ${ }^{1}$.

${ }^{1}$ The writer takes this opportunity to express his sincere appreciation of the assistance, guidance and kindly counsel of Dr. J. Jost, head of the Botanical Department of the University of Heidelberg, and to his able assistants. 
The results of the work have not been published before because of lack of time to complete many of the details which should be more carefully investigated. There is still much to be done, and the present report is only a beginning of a more thorough study that the writer hopes to publish as he has opportunity to pursue the subject further. The present description of the midrib structure is presented at this time because of its relation to the study of vein-rot as described in a later section of this report.

Subsequent to the initiation of this investigation, Avery ${ }^{1}$ has published three excellent papers dealing with the structure of the tobacco leaf. These constitute our most important contribution to this subject. Avery deals particularly with the origin and development (ontogeny) of the different kinds of tissues during the growth of the leaf, while in the present investigation we are interested only in the fully developed tissues of the mature leaf. Nevertheless, the fields of the two investigations (using the same types of tobacco, all grown in Connecticut) overlap in large areas; and in these areas our results have confirmed in every detail those of Avery. Our excuse for publishing those parts which largely duplicate Avery's findings, is that this bulletin will be distributed to a different group of readers who may never have occasion to see the journals to which Avery has contributed. In the second place it is desirable to give the reader a complete picture here without referring him to other publications which may not be accessible to him.

In Comnecticut types of tobacco, the leaf has no petiole (leaf stalk) and therefore the midrib ${ }^{2}$ extends from the main stalk of the plant up through the center of the leaf to its extreme tip. At its point of insertion on the stalk, the midrib of the Havana Seed variety, which was used in this investigation, is about one-half inch thick and tapers upward regularly to a small thread at the tip of the leaf. On the upper side it is almost level with, or even sunken groove-like somewhat beneath the level of the upper surface of the blade of the leaf. But on the under side it projects from the level of the lower surface of the leaf as a prominent, half-round vein. The insertion of the leaf blade at the upper angles of the vein is shown in Figure 10 which is a photograph of a thin cross-section of a midrib magnified about 15 diameters.

This same photograph also shows in cross-section the principal tissues of the vein. The epidermis is one layer of small cells around the entire outside of the section. Just beneath the epidermis is the chlorenchyma, two or three layers of small cells which appear green in a fresh section because they alone contain chlorophyll which gives green color to the vein. Inside the circle of the chlorenchyma layer is the cortex, a broad layer of large, thin-walled cells which constitutes the largest bulk of the vein. In the center of the picture is a promment downward-curved arch of cells of an entirely different appearance and structure. This is the vascular

\footnotetext{
${ }^{1}$ Avery, George S. Structure and germination of tobacco seed and the developmental anatomy of the seedling plant. Am. Jour. Bot. 20: 309-327. 1933.

Structure and development of the tobacco leaf. Am. Jour. Bot. 20: 565-592. 1933. Structural responses to the practice of topping tobacco plants. Bot. Graz. 96: 314-329. 1934.
}

:In the tobacco trade the midrib is commonly referred to as the "stem". Thus the process of "stemming" in cigar factories and elsewbere refers to the removal of the midrib from the blade of the leaf. Bot anically speaking, this use of the term "stem" is incorrect. "Midrib" and "midvein" are the terms used in this bulletin. 
arch and is functionally the most important part of the vein. Immediately surrounding the vascular arch is a circle of small cells, the pericycle. Each of these tissues can now be described more in detail.

\section{Epidermis}

The epidermis of the midrib is composed of slender, parallel cells, as shown in Figure $12 \mathrm{~A}$, the long axis of the cells in the same direction as the length of the vein. As seen in surface view, the cells are irregularly fusiform polygonal in outline with the tapering ends dove-tailing. The cells are 200 to 300 microns long by 25 to 60 microns wide. In crosssection (Figure $12 \mathrm{C}$ ) they are somewhat quadrangular. The outer wall is covered by a thick, water-proof cuticle which makes it appear much thicker than the other walls. There are no chloroplastids in the unmodified epidermal cells. Two modifications of the epidermis require special description.

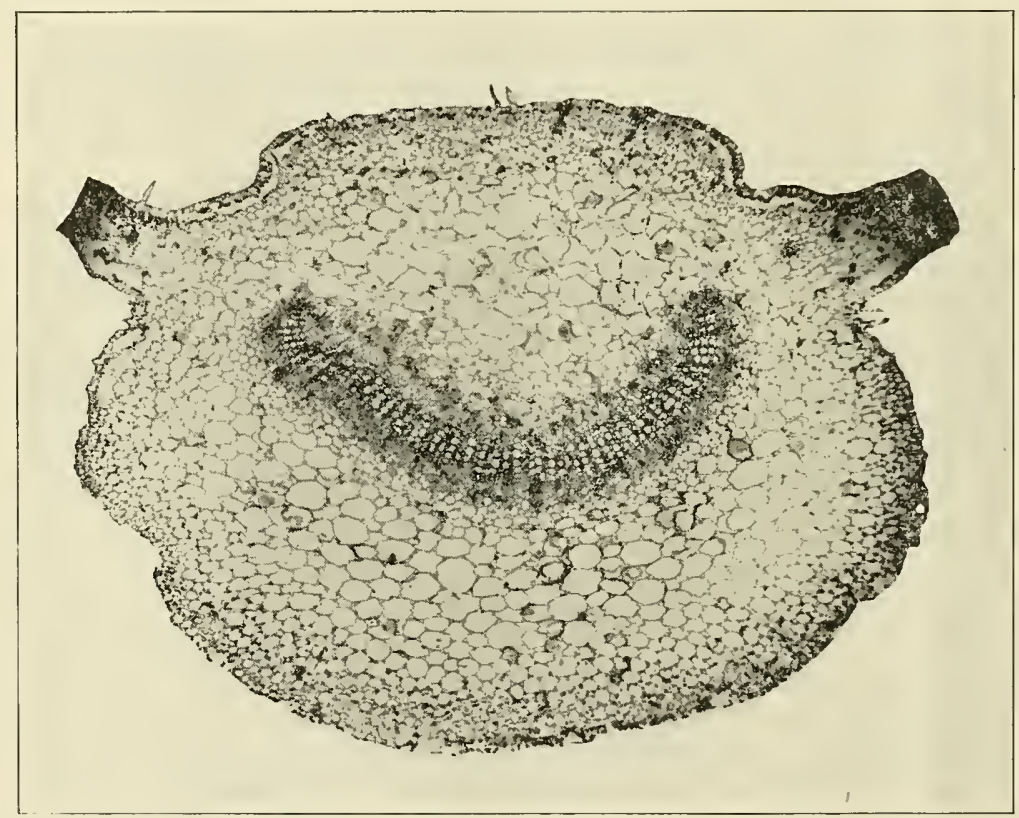

Figure 10. Cross-section of midrib stained with haematoxylon. The hornlike projections at the upper left and right show the points of attachment of the leaf blade.

The Glandular Hairs. When the leaf is young, the midrib is hirsute with white, straight hairs (Figure 11). As it becomes older, the hairs are not so noticeable, although they do not disappear. The hairs are straight-sometimes slightly curved-simple, undivided and vary greatly in length from 200 microns up to 2 millimeters, and in diameter from 
20 to 150 microns. Each hair rises directly from the center of an epidermal cell (Figures $12 \mathrm{~B}$ and $12 \mathrm{C}$ ) and the wall between the base of the hair and the top of the epidermal cell appears thin since it has no cuticle. The shape of the hairs is shown in Figure $12 \mathrm{~F}$. The stalk consists of two to five hyaline cells tapering from the base upward. At the tip of most of the hairs there is an enlarged knob-the gland - which is densely filled with coarsely granular protoplasm and globules of a brown or greenish material that completely permeates the interior of the cells and also appears on the outer surface as a ragged, sticky exudate. Typically, the apical gland consists of one oval cell-or is divided by a cross-wall into two cells. However, glands of three to six cells are not infrequent. Sometimes there are also vertical septa in addition to the more usual horizontal ones (Figure $12 \mathrm{~F}$ ).

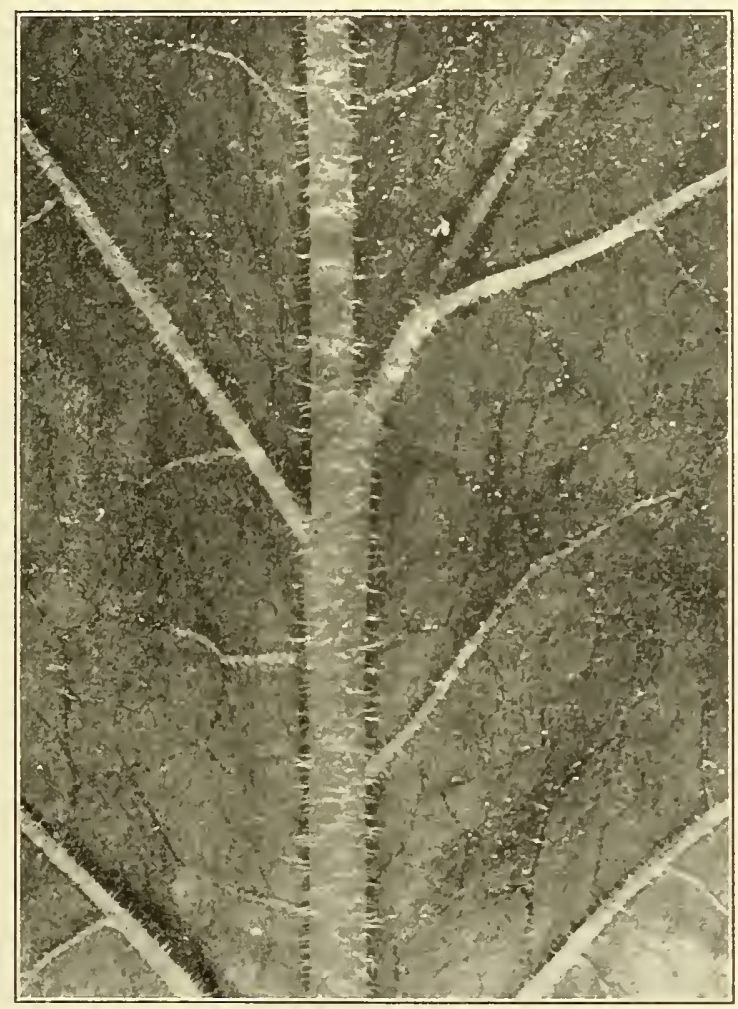

Figure 11. Midrib of young leaf showing glandular hairs.

The-secretion that exudes to the surface of these apical glands is the well known gum that makes the leaves feel sticky and that stains the hands of workmen with a thick, black, tenacious layer that is difficult to wash off even with soap and water. This gum has not been investigated chemically and its functions and properties are little known. It remains on the leaf surfaces during curing but disappears almost entirely during the fermentation process. Since it could possibly have a distinct influence 

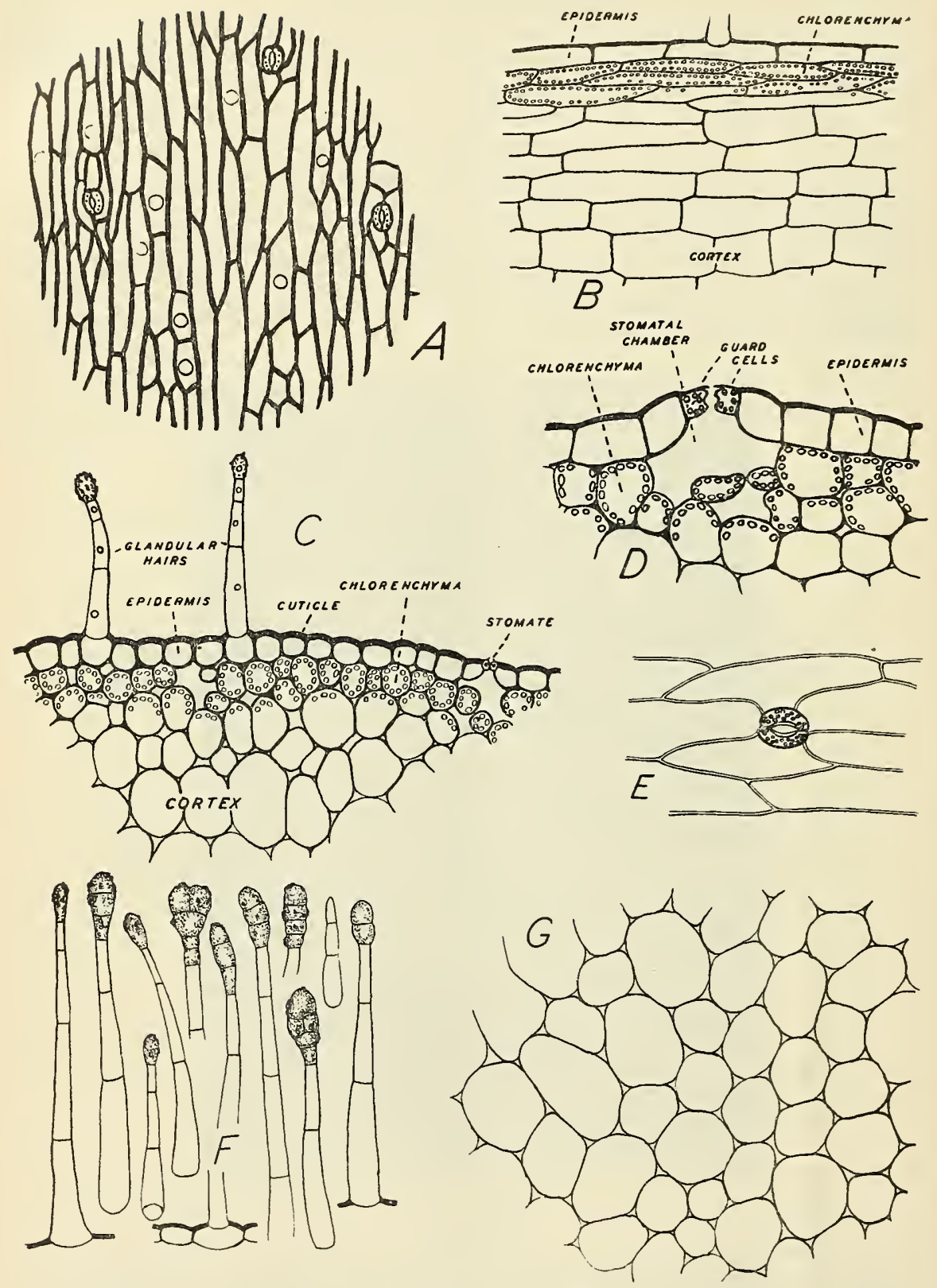

Figure 12. Anatomy of the Midrib

A. Surface view of the epidermal cells. B. Longisection of epidermis, chlorenchyma and cortex. C. Cross-section of same tissues. D. Cross-section of a stomate. E. Surface view of a stomate and adjacent epidermal cells. F. Glandular hairs. G. Cross-section of cortex cells. 
on the taste, aroma, combustion or other properties of the cured leaf, it is worthy of closer investigation.

The hairs on the midrib are morphologically the same as those on both surfaces of the leaf blade, but on the midrib they are more numerous and in general appear to be longer than those on the blade of the leaf.

The Stomates. There are stomates, "breathing pores", on all surfaces of the midrib. They are not nearly so numerous as in the epidermis of the leaf blade. Their frequency is indicated in Figure $12 \mathrm{~A}$. Figures $12 \mathrm{~A}$ and $12 \mathrm{E}$ also show the configuration of the epidermal cells around them. The stomate originates by late divisions of the expanding cells and consequently the cells immediately surrounding it are smaller than the regular cells of the epidermis. Looking down on the stomate (Figure $12 \mathrm{E}$ ), one sees two bean-shaped guard cells facing each other on their concave surfaces and leaving thus a lenticular opening which permits the exchange of gases between the outside and the interior of the leaf and allows the water to pass off as vapor. The opening is partly closed, however, by a thin membrane which appears as an extension of the cuticle, but with a slit through the center. The guard cells contain chloroplastids and are the only cells of the epidermis in which these green bodies occur. In cross-section of a midrib, the stomate appears as shown in Figure $12 \mathrm{D}$ where it will be noticed that the guard cells are raised somewhat above the level of the others. Directly beneath the guard cells is an open space -stomatal chamber-and the cells surrounding the chamber are not packed tightly together but are loose to allow gases to pass between them.

\section{Chlorenchyma}

The chlorenchyma consists of two or three layers of cells immediately beneath the epidermis. In size and shape these cells are similar to the epidermal cells except that when seen in longisection (Figure 12 B) the ends are more pointed and inclined to slip past each other in dovetail. The walls are not so thick as those of the epidermis but distinctly thicker than those of the cortex cells. As seen in cross-section (Figure 12 C). they are thickened at the corners, i. e., the triangular spaces between three abutting cells are filled in solid (collenchyma). Thus the chlorenchyma layer serves as a stiff supporting and protecting collenchyma ring for the softer underlying cells. The solidity of this ring is broken only beneath the stomates where there are large intercellular spaces and no collenchymatous thickening, thus allowing free circulation of air and gases.

The characteristic feature of the chlorenchyma layer is the presence of the green chloroplastids embedded in a protoplasmic layer which lines the walls of the cells. These are most numerous in the outside layer of cells, somewhat less in the next layer and only scattered in the next one or two below. The chlorophyll pigment which is in the chloroplastids gives the green color to the vein and, with the exception of the guard cells of the stomates, it is confined to the chlorenchyma layer.

\section{Cortex}

All of the space between the chlorenchyma ring on the outside and the vascular bundle at the center is filled by large, thin-walled parenchyma cells. This tissue, the cortex, occupies the greater part of the vein, is 
white, spongy and filled with sap. In a cross-section of the vein, the large cells, 150 to 250 microns across, are seen to be almost round. Between them there are regularly triangular intercellular spaces (Figure $12 \mathrm{G}$ ). In longisection the cells appear brickshaped and are two to four times as long as broad (Figure 12 B). Except for a thin layer of protoplasm around the walls, they contain only a watery sap.
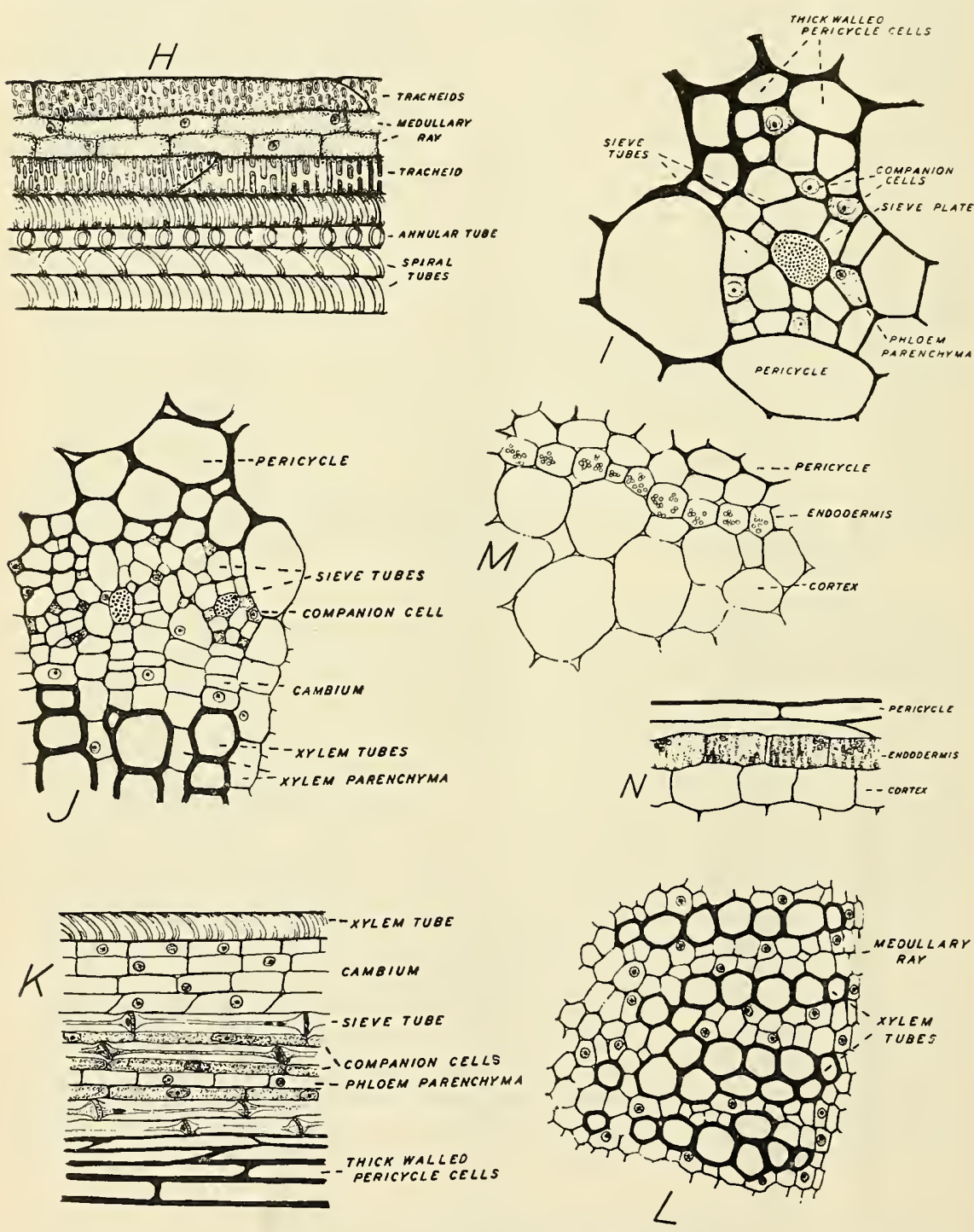

Figure 13. Anatomy of the Midrib

H. Longisection of the xylem elements. I. Cross-section of an internal phloem area. J. Cross-section of an external phloem area. K. Longisection of phloem. L. Crosssection of xylem. M. Cross-section of endodermis. N. Longisection of endodermis (all drawn with the aid of a camera lidida). 


\section{Endodermis}

The cortex is separated inwardly from the pericycle by a single layer of cells, the endodermis. In many plants the cells of the endodermis are very distinct and differ in size, shape, and other characteristics from the surrounding cells. In the vein of the tobacco leaf, however, they differ little from the cells about them and they are not readily distinguished by position, regularity, shape or size, so that their classification as a distinct tissue seems almost superfluous. They may be located in crosssection by the fairly abundant starch grains they contain (Figure $13 \mathrm{M}$ ), and in longisection by the presence of their abutting walls of striations, known as Casparian strips.

\section{Xylem}

The xylem, water conducting tissue, occupies the center of the vascular bundle. In cross-section, the water tubes, tracheae and trachieds, appear as radiating rows of large, round or somewhat angular, thickwalled cells (Figure 13 L and Figure 14). There are one or two rows of tubes in each ray. They are 20 to 65 microns across and the walls are about 3 microns thick. The number in each row varies naturally with the size of the vein. Figure $13 \mathrm{~L}$ represents the condition about half way between tip and butt of a mature leaf.



Figure 14. Enlarged section of the xylem. Shows rows of xylem tubes with xylem parenchyma cells between them.

Between the rows of tubes are rays composed of one to three rows of thin-walled parenchyma cells. The xylem parenchyma cells contain large nuclei, protoplasm and many leucoplastids. They are shown in longisection in Figure $13 \mathrm{H}$. The xylem tubes are of two kinds, tracheae and tracheids, the former being long, continuous tubes like water pipes, while the latter are shorter and have diagonal or blunt ends (Figure $13 \mathrm{H}$ ). The walls of all of the xylem tubes have regular thickenings on the inside which reinforce them and keep them from collapsing, while the thin parts between the thickenings permit water and dissolved salts to pass more easily from cell to cell. The thickenings on the tracheae are either 
in the form of rings-like the hoops around a barrel except that they are on the inside - or in the form of a regular spiral, like a wire spring. The number of spirals varies from one to four or five around each tube. The thickenings on the tracheids may also be rings or spirals, usually with frequent anastomosing cross members. When the cross members are numerous it makes the wall appear reticulate. More commonly, however, the walls are completely thickened except for small dots or slits which appear transparent under the microscope. Thinner borders to the slits give the bordered pit effect shown in some of the tracheids in Figure $13 \mathrm{H}$.

The xylem tubes are hollow and contain no nuclei or protoplasm.

\section{Cambium}

Just outside the xylem on the convex (lower) side of the vascular bundle are several layers of thin-walled, very regular, brick-shaped cells, which constitute the cambium (Figure $13 \mathbf{J}$ and $\mathbf{K}$ ). They are filled with protoplasm and have large nuclei. While the leaf is growing and expanding, these cells divide repeatedly and the daughter cells which split off on the inside are transformed into xylem elements. Those that split off on the outer (lower) side are transformed into phloem and pericycle cells.

\section{Phloem}

The phloem is the tissue that serves for transport of food, which has been elaborated in the leaf, to other parts of the plant. In the tobacco leaf, we distinguish two kinds of phloem which differ only in position and origin but are identical in function and in the morphology of the elements that compose them. The phloem areas just outside the cambium on the convex (lower) side of the vascular bundle are called external, while the isolated areas on the concave side, not contiguous to any cambium but entirely surrounded by pericycle cells, are the so-called internal phloem. An internal phloem area is shown in cross-section in Figure 13 I and an external area in Figure $13 \mathrm{~J}$.

Regardless of position, the phloem is composed of sieve tubes, companion cells and some phloem parenchyma cells. The latter are irregular in occurrence and position and are no different from the xylem parenchyma cells. All phloem groups studied have regularly about an equal number of sieve tubes and companion cells. Although both kinds of cells are irregular in shape and size, the companion cells are always smaller in diameter than the sieve tubes. The companion cells may also be quickly detected by their coarse, granular, deeply staining protoplasmic contents, and by their large nuclei usually elongated in the direction of the long axis of the cells (Figure $13 \mathrm{~K}$ ).

The sieve tubes are usually somewhat irregularly polygonal in crosssection, larger than the companion cells and rather irregularly arranged in the phloem, but each sieve tube is always contiguous to at least one companion cell. They are also not uniform in length but usually not less than 10 times as long as broad. The continuous tube is formed of many cells set end on end. The abutting end-walls are the so-called sieve plates which are perforated with numerous minute pores arranged like the holes of a sieve or a household colander. These sieve plates with their numerous perforations characteristic of the sieve tubes may 
best be seen in stained cross-sections (Figure $13 \mathrm{I}$ ). The plates are usually not at right angles with the side walls, but are somewhat tilted and frequently curved upward or downward at the center. The only cell content is a narrowed strand of protoplasm that stretches from one sieve plate to the next through the center of the lumen (Figure $13 \mathrm{~K}$ ). This protoplasmic strand widens out to the entire diameter of the lumen at the plates as shown in the figure. In favorably stained sections, the strand as it leaves the plate appears to be composed of numerous parallel fibers, as if there were a fiber passing through each hole, and these unite in the center of the cell to form the strand. There is no nucleus in the cell. Frequently, however, there is a dark-staining mass of material in this strand, at or near the plate, which may be a disintegrated nucleus or the so-called slime plug. The protoplasm of the strand is otherwise very fine and uniform without granules or plastids of any kind. The appearance of the phloem elements in longisection is shown in Figure $13 \mathrm{~K}$, and in cross-section in Figures $13 \mathrm{I}$ and $13 \mathrm{~J}$.

\section{Pericycle}

The tissue which is outside the phloem or between the phloem areas but inside the endodermis is the pericycle. There are essentially two classes of cells in the pericycle. The part of the pericycle nearest the cambium is composed of short parenchyma cells, like the parenchyma of the xylem and phloem. Also they form a part of the outer pericycle. The other class of pericycle cells are much longer and with more pointed,

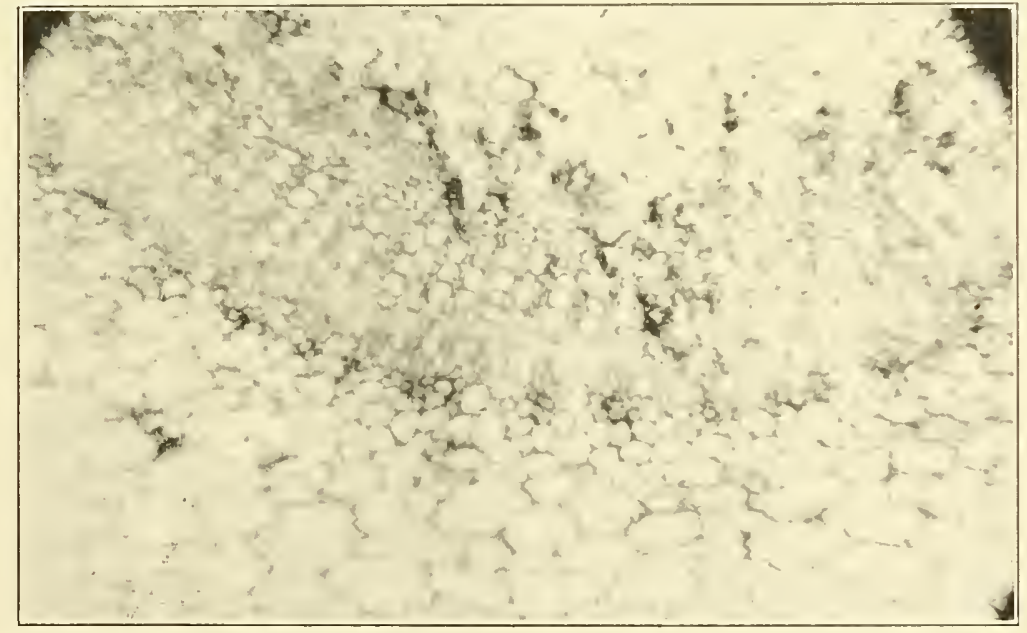

FigUre 15. Photomicrograph of cross-section of vascular bundle. Shows the thick-walled pericycle cell in a semi-circle of darkened areas at bottom of vascular bundle.

overlapping ends. The walls of these cells are more or less thickened. They are especially prominent in somewhat regularly spaced groups outside the phloem and just inside the endodermis where the walls become extremely thick (Figures 13 and 15). They probably serve as bast fibers for strength and rigidity and may protect the more delicate phloem areas adjacent to them. 
TOBACCO DISEASES IN 1936

P. J. Anderson

Although no systematic survey of the tobacco growing section of Connecticut was undertaken in 1936, the writer is thoroughly conversant with the situation. The staff of the Tobacco Experiment Station is in constant touch with the growers. Throughout the season we have made frequent trips to all parts of the tobacco section, have talked with many growers on their farms and during visits to the Station and believe, therefore, that during such a year as we have had, a detailed census of diseases would represent wasted time and would add nothing of real value to the farmers. Compared with other years, the crop here has been remarkably free from disease. Some of them have not been seen at all and others only in very small amount. The season as a whole has been quite favorable to growth of the crop, perhaps a little too dry for the spread of disease. The early part of the season (June), however, was unusually cool and caused slow growth and some root trouble.

\section{Observations and Notes on Prevalence of Diseases}

Pythium damping-off in seed-bed (Pythium debaryanum). A. very few cases were observed but it was not prevalent.

Bed rot on older plants in the beds (Rhizoctonia). A few cases of this trouble are noted every year but this year there were fewer than usual. The cases observed were not extensive enough to cause serious loss.

Wildfire (Bacterium tabacum) was found in only three seed-beds and in four fields. In one of the fields the farmer pulled up all plants and set new ones from a bed not infected. This disease did not appear again. Total loss to the crop in the Valley as a whole was negligible.

A wildfire resistant strain of tobacco. During the years when wildfire was a very serious disease here- -10 or 15 years ago-the writer spent a great deal of time and effort in trying to find or develop a single plant or strain that showed any resistance to this disease. All efforts, however, were without success. Other American investigators likewise failed to bring to light any hopeful sign of resistance in American varieties of tobacco. In 1929, however, articles began to appear in the German newspapers and journals in regard to a strain of German tobacco (Amesfoorter) which was claimed to be resistant, the claim being supported by data on scientifically conducted experiments.

The writer secured a sample of seed of the resistant strain from the Tabakforschungsinstitut für das Deutsche Reich at Forchheim bei Karlsruhe through the courtesy of the Director, Dr. J. Koenig. This was planted in the greenhouse at Windsor and the seedlings transferred to pots. When they were six to eight inches high, they were inoculated with a pure culture of the wildfire organism. At the same time, other plants of our Broadleaf variety were inoculated. All pots were kept for about a week in a large glass chamber to give favorable moisture conditions 
for infection. All developed typical and numerous wildfire spots and there appeared to be no differences in severity of infection between the Broadleaf and Amesfoorter. No tests were tried in the field.

Blackfire (Bacterium angulatum). This disease was observed occasionally but was not causing measurable loss.

Frenching. This is a rare disease in Connecticut but occasionally we find a small affected spot in a field. Invariably such spots have a high soil reaction (above $6 \mathrm{pH}$ ), but in other respects, soil tests show no consistent differences between affected and normal parts of the same field. For the first time in our experience, we found this year a case of frenching in the seed-beds. The plot where this bed was located had previously been used as a chicken yard. Soil tests showed the high reaction (over $6 \mathrm{pH}$ ) and a high degree of fertility with respect to calcium, potash and magnesia, but a low content of nitrate or ammonia nitrogen. Some of the affected plants were set in pots, others in the field. All quickly recovered and developed into normal, mature plants.

Black Rootrot (Thielavia basicola). Black rootrot was not observed in the seed-beds this year. During the early part of the season, which was marked by lower temperatures than usual, it was observed in fields of all three types of tobacco, causing slow growth and stunting of the plants. During the hot weather of July and August, however, these fields recovered and made what appeared to be a normal growth. Whether the early infection resulted in any ultimate depreciation in yield or cuality could not be determined.

Brown Rootrot. The occurrence of brown rootrot in a few fields in 1936 could be readily explained. The fields had been previously used for cereals which predispose the soils to this trouble when tobacco is set here. Most of these did not make a full recovery later in the season and the depreciation in yield and quality was sufficient to wipe out all expected profit. In the case of the shade fields, it caused considerable net losses. Fortunately, this season there were only a few, relatively small fields where tobacco was planted following such cereals.

Mosaic (Virus). This trouble can be found every year and usually on every farm, but the net loss is usually quite small and the disease is not considered a major trouble by most growers. Occasionally a field is found where the infection becomes general early in the season, resulting in serious loss. No such fields were heard of this year, and on the whole the disease was less prevalent than usual. The Broadleaf variety usually suffers most and the shade variety least. In 1936, however, there was more than the usual amount of mosaic in some fields of shade tobacco. Origin of such infestations was not determined.

At various times the writer has attempted to calculate or estimate the actual percentage loss of the whole crop from mosaic, but such estimates are so complicated by the differences in severity on different farms, and by guesses on actual loss when infection occurs at different stages of growth, that the resultant figures are of questionable value. Probably the loss is never as heavy as 1 percent of the entire crop, although on certain farms in certain years it is much higher. 
Mosaic resistant Broadleaf. All types of tobacco grown in the United States are susceptible to mosaic, and all attempts to find a resistant plant have been futile. In the last few years, however, Dr. J. A. B. Nolla, of the Department of Agriculture of Puerto Rico, discovered a type of South American tobacco, Ambalema, which is immune to this virus trouble. Doctor Nolla very kindly furnished a sample of the seed to the writer from which a crop was grown to maturity in the greenhouse. Inoculation tests failed to produce any mosaic symptoms on the plants although the same tests produced disease readily in other types of tobacco growing in the greenhouse at the same time. Investigators in other states have fully demonstrated the resistance of this type of tobacco.

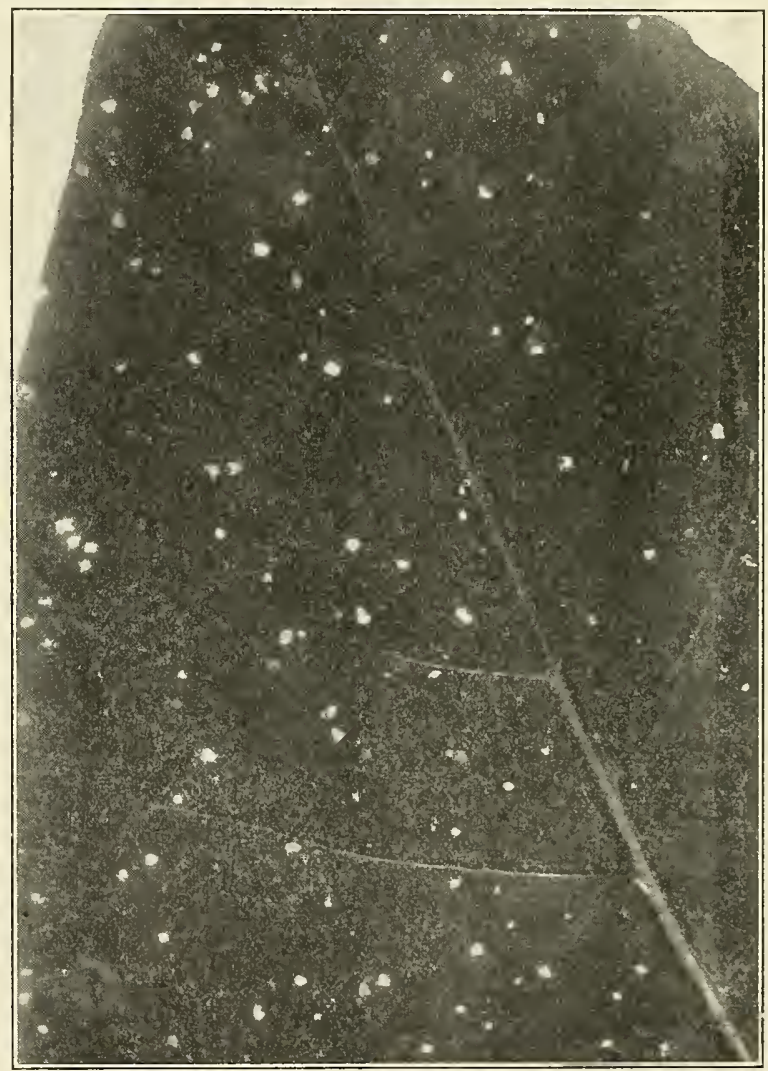

Figure 16. Brown Spot on shade tobacco. Spots appear white because a filter was used in taking the photograph.

Unfortunately Ambalema is a type entirely different in habit and qualities from our Connecticut types of tobacco and therefore commercially is of no use to us. There exists, however, the possibility of crossing it with our tobacco and of getting from the progeny of such a cross a type that is identical with ours but which has the resistance of Ambalema. 
Such a project would probably require many years of selection and testing and might never be successful. To test out its possibilities, however, Ambalema was crossed with John Williams Broadleaf in 1936. Seed from the hybrids are now being produced in the greenhouse, and the $F_{2}$ generation will be grown and tested in the field in 1937.

Brown spot on shade tobacco (Physiological). This is never a very serious disease but in several shade fields was found in more than the usual amount this year. On this variety the spots are slightly different from those found on our other varieties, being usually smaller and more regular in outline. On shade they are usually about an eighth of an

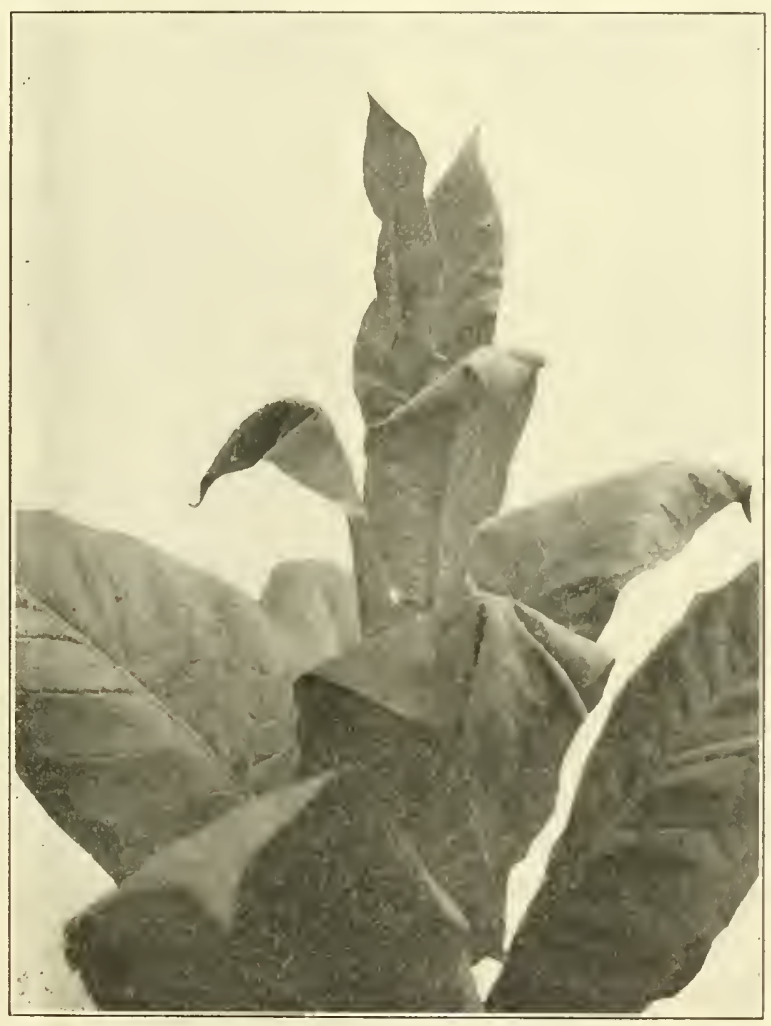

Figure 17. Sunburn. The young, scorched leaves fail to recover even when watered, and the tips hang limp.

inch in diameter, quite circular in outline, numerous on a leaf, dark chestnut brown on both surfaces, without concentric rings (Figure 16). As in previous years microscopic examination and isolation experiments failed to show any organism connected with the spots.

Weather injuries. There was no serious hail or wind damage during the present year and no case of lightning injury came to our notice. During 
the excessively hot weather of July, when the temperature approached $100^{\circ} \mathrm{F}$. for several days, many of the tender younger leaves were scorched. The wilted parts of the leaves hung $\operatorname{limp}$ and did not recover even when water was added (Figure 17). Such injury was confined to the more sandy parts of the farms where the leaves were wilted. Large areas on these leaves turned black and after several days bleached out, leaving the foliage distorted, torn and worthless (Figure 18).

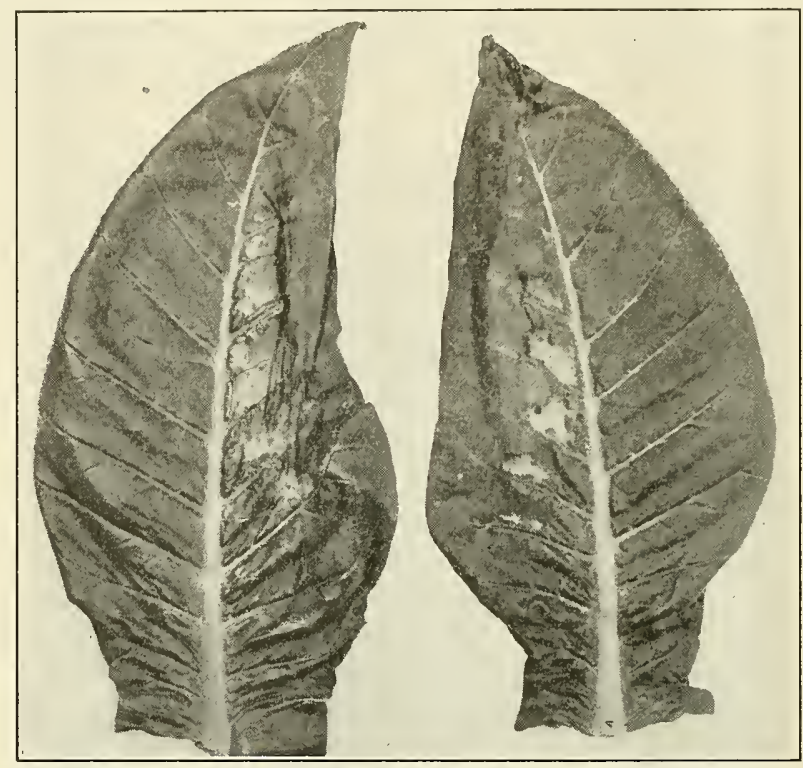

Figure 18. Sunburn. The burned areas bleached out causing distortion of the leaves

Pole rot (Alternaria tenuis and other fungi). Crops that were harvested early cured without much pole rot. Late harvested crops, however, were in a dangerous stage during a considerable period of damp weather and there has been some damage. The extent of such damage cannot be determined until the tobacco is sorted.

\section{Studies On Pole Rot. II. Vein-rot}

The first of a series of articles on this disease was published in our report for $1935^{1}$. This second article is a continuation of the first, and the reader is referred to the former publication for a general statement of the situation and review of previous work. As stated in 1935, the first objective of these studies is to make a thorough investigation of all fungi or other organisms found on affected leaves that might have a connection with the trouble. The term "pole rot" is a general inclusive name applied to what is probably a group of diseases caused by different

${ }^{1}$ Studies on Pole Rot. I. Conn. Agr. Exp. Sta. Bul. 386: 600-607. July, 1936. 
organisms and exhibiting different symptoms. The only common characteristic is that they all cause a decay of the leaves during the curing period in the shed. On the basis of symptoms, the writer distinguished three kinds of pole rot: (1) freckle rot, (2) web rot, and (3) vein rot. The previous article dealt only with the freckle rot type which was found to be caused by the invasion of fungus, Alternaria lenuis, into the tissues of the leaf blade. In this second article, he begins consideration of the type which has been designated as vein rot, popularly known also as "stem rot".

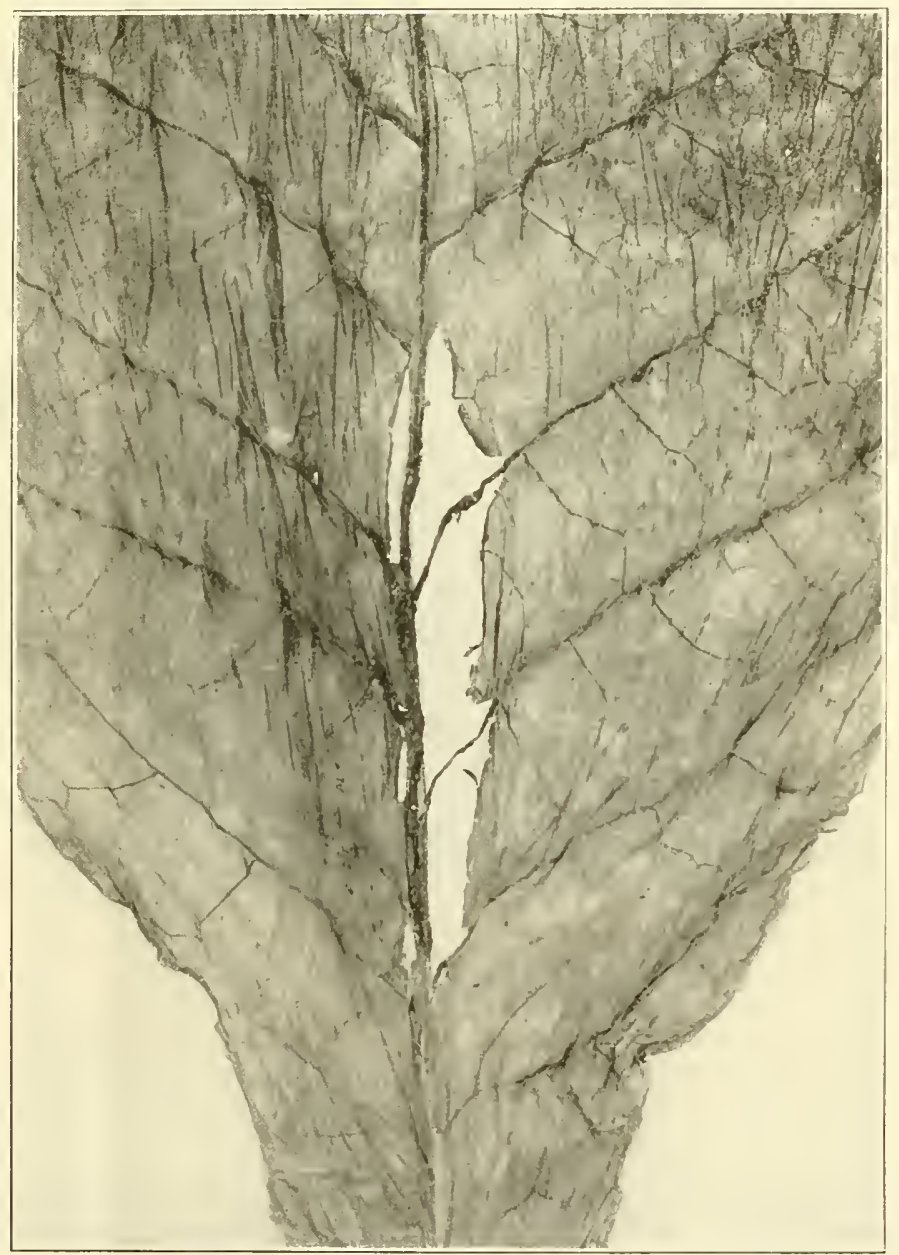

Figure 19. Pole rot. Vein-rot type on cured tobacco leaf.

As its name indicates, this malady affects the reins of the leaf, being found most often on the midvein, but sometimes on the larger lateral veins as well. During the curing process, the reins remain alive longer 
than any other part of the leaf. The large midrib especially retains considerable moisture for several weeks, and after its cells are weakened and begin to die, its moist, soft condition makes it a favorable subject of attack for various fungi. Often these fungi grow on the midrib without causing any permanent damage, especially if the latter part of the curing season is not too prolonged and the midrib dries out quickly. Under less favorable curing conditions, however, the rot continues until the vein is soft and decayed and the blade splits away from it when one attempts to open the leaf (Figure 19). Frequently the tissues adjacent

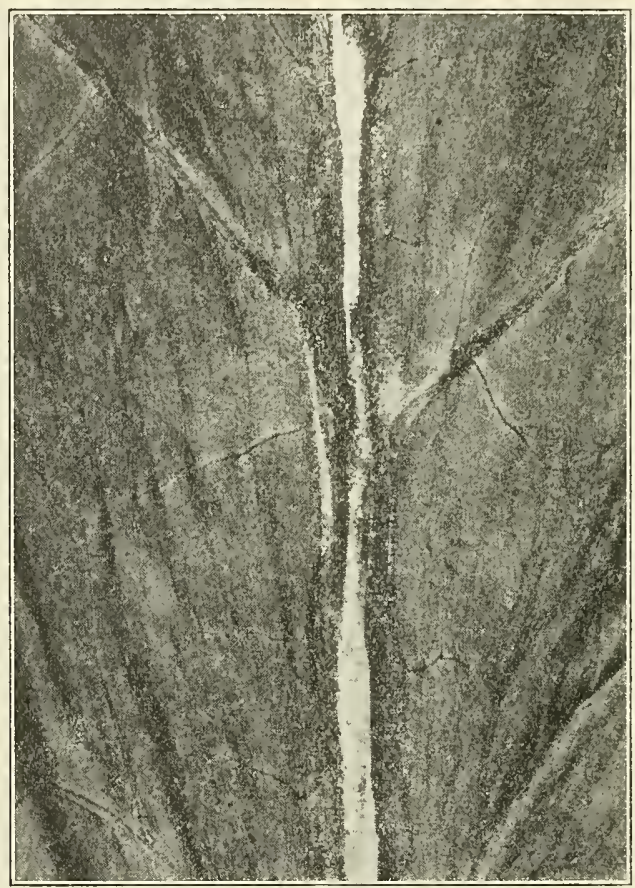

Figure 20. Early stage of vein-rot. White streaks of Alternaria mycelium on the surface of the midrib.

to the midvein are also rotted. One may watch the progress of the disease in the curing shed. The first symptoms appear after the veins have lost their green color and have turned to a straw yellow and often after the blade of the leaf is cured. Darker streaks or patches, usually somewhat sunken, appear on one or both surfaces of the vein. Soon white, felt-like tufts of mycelium grow out from the centers of these darker streaks or entirely cover them (See Figure 20). As the disease progresses, the white tufts become black, gray, pink or other colors, depending on which species of fungus is present. During the present year, the writer found species of Alternaria, Botrytis, Fusarium, Cladosporium and other unidentified genera on affected leaves. It is not certain that all of these cause damage. 
Alternaria, the common fungus this year. The most common one found this season was Allernaria tenuis. Therefore an intensive study was made of this species and the type of damage which it caused. The type of vein-rot described below is that caused by Alternaria alone. Those caused by Botrytis and other fungi are reserved for future articles. The white tufts of mycelium of the Altermaria gradually turn to gray and soon afterward to black due to development of spores on the surface. These spores were studied and measured and found to be the same as we have previously described for Alteraria lenuis'.

Isolations. Numerous isolations were made from the interior tissues of the midvein: (1) directly under the tufts; (2) on the opposite side of the rib; and (3) from the edges of the sunken lesions where there were no surface tufts. With the exception of a few that were on the extreme edge of the lesions, all of these tissue transfers gave pure cultures of Alternaria. There can be no doubt, therefore, that the mycelium which can be seen in the interior of these lesions is that of Alternaria tenuis. Bacteria were not present in the younger lesions. In thoroughly rotted veins, however, bacteria and other fungi were sometimes found.

Inoculation experiments. In order to prove conclusively that this particular species of fungus is the cause of this type of pole rot, it is necessary to inoculate curing leaves with pure cultures of the fungus and produce the disease on the veins. To isolate Alternaria in pure culture from the interior of the vein is a simple and easy operation; but to inoculate leaves in the shed under natural conditions and produce the malady without the complications of other fungi whose spores are ommipresent on the curing tobacco, is not simple, and as yet the writer has found no satisfactory method of accomplishing this. However, the following experiment presents very strong evidence of pathogenicity of the organism, although admittedly subject to the objection that the conditions were somewhat artificial.

Midribs from half-cured tobacco were cut into sections about two inches long and sterilized on the surface in three different ways: (1) by washing in alcohol and then in sterile water; (2) dipping in alcohol and then burning the alcohol off; (3) steaming for three to five minutes. They were then placed on agar plates for several days to see whether there were still any organisms on them. Those that developed any growth on the agar, and thus showed that they were not sterile, were discarded. The third method was successful in sterilizing all, but only about half the others remained sterile. Those sections that remained sterile were then transferred to sterilized test tubes (without agar) and inoculated on the uncut surface from pure cultures of Alternaria. Others were left uninoculated as controls.

The fungus quickly spread over the surface of the vein segment and within a week was found inside the tissues. In ten days the pieces were soft and rotten and within two weeks when examined under the microscope all the cells except the central xylem tubes had disintegrated. The entire interior was filled with a dense tangle of hyphae. Transfers from the interior gave pure cultures of Alternaria. Under these conditions, therefore, this organism is capable of causing a complete decay of the vein.

${ }^{1}$ Spores and mycelium are illustrated and described in Conn. Agr. Exp. Sta. Bul. 36i: 132, and Bul. 386: 606 . 
Penctration of the epidermis. After the spores of the fungus germinate on the surface of the midrib, there are several avenues by which the germ tubes might conceivably reach the interior of the vein. They could easily enter through the stomates which are found on all surfaces of the veins, although not so numerous as in the epidermis of the leaf web. The opening of such stomates was found to be 20 to 30 microns long by 5 to 8 microns wide, when well opened. Since the germ tube is only 2 or 3 microns in diameter, it could easily pass in through these openings. It might also pass directly through the cells of the epidermis or through the basal cells of the glandular hairs that are so numerous on the midribs. Another possibility would be injuries which are inevitable during the harvesting process.

In an attempt to determine how penetration occurs, the following experiment was carried out: A strip of epidermis removed from a leaf was used to cover a thin block of potato dextrose agar on a glass microscopic slide. A small drop of water containing Alternaria spores was transferred with a loop to the surface of the epidermis and the slide placed in a moist chamber. Microscopic examination at intervals for the next 36 hours revealed that the spores began to germinate within two hours, sending out 1 to 4 germ tubes which branched and grew rapidly over the surface of the epidermis. The stomates were mostly tightly closed and the germ tubes passed directly over them. In some instances, however, the germ tubes were found passing through the more open stomates, obviously to reach the nutrient agar below.

Tisdale and Wadkins ${ }^{1}$ working with a species of Alternaria that was probably the same as Alternaria tenuis found that in producing the leaf spot of tobacco which they were investigating, the germ tubes usually passed through the stomates but sometimes directly through the epidermal cells or through the basal cells of the hairs.

Mycelium inside the tissues of the midrib. Progress of the mycelium of the fungus through the tissues of the midribs was studied by free-hand razor sections and by stained microtone sections. ${ }^{2}$ All parts of the midrib down to the central arch of xylem elements were found to be invaded and in one place the mycelium was penetrating the medullary rays between the xylem groups. Ultimately it destroys all the cells of the vein except the xylem tubes but it had not yet progressed to that stage in the material studied. The hyphae pass both between the cells and through them. They were found in the epidermal cells, including the guard cells of the stomates and the cells of the glandular hairs, in the collenchyma cells just beneath the epidermis, in the cortex cells, endodermis, thick-walled and thin-walled cells of the pericycle, in the phloem and cambium. The hyphae are most abundant and seem to grow most luxuriantly in the cortex, causing these cells to collapse and fall together, but in the early stages the walls remain intact. The other cells, having thicker, stiffer walls, keep their shape much longer without collapsing. (See Figure $21 \mathrm{~A}$ ). As the hyphae advance into

${ }^{1}$ Tisdale, W. B., and R. F. Wadkins. Brown spot of tobacco caused by Alternaria longipes. Phytopath. 21: 641-660. 1931 .

${ }^{2}$ Small pieces of affected midribs, showing young lesions and tuf ts of mycelium on the surface, were killed in Gilson's solution, dehydrated through the grades of alcohol, through xylol into paraffin and sections of about 10 microns thickness stained with haemotoxylon and erythrosin or with Flemming's Triple Stain. 
the deeper tissues, they first push between the cells. In doing so they utilize the intercellular spaces but they are also able to force their way between cells where there are no intercellular spaces, probably by dissolving the middle lamella. In a trans-section, the hyphae appear imbedded in the walls, causing the walls on either side to bulge inward into the lumina of the cells. (See Figure 21). But soon hyphae pass directly into and through the lumina of the cells (Figure 21 A) becoming very much constricted at the points where they pass through the walls from one cell to the next. The hyphae are very irregular in diameter, varying from 1.5 microns up to 15 microns (usually 3 to 7 microns), in shape and direction, often forming the large subglobose cells that we have described in previous reports. The hyphae are hyaline but filled with dense granular protoplasm that stains deeply with the various stains used. The cells of the host contain very little protoplasm at this time and no study was made of the effect of the invasion on the cell contents.
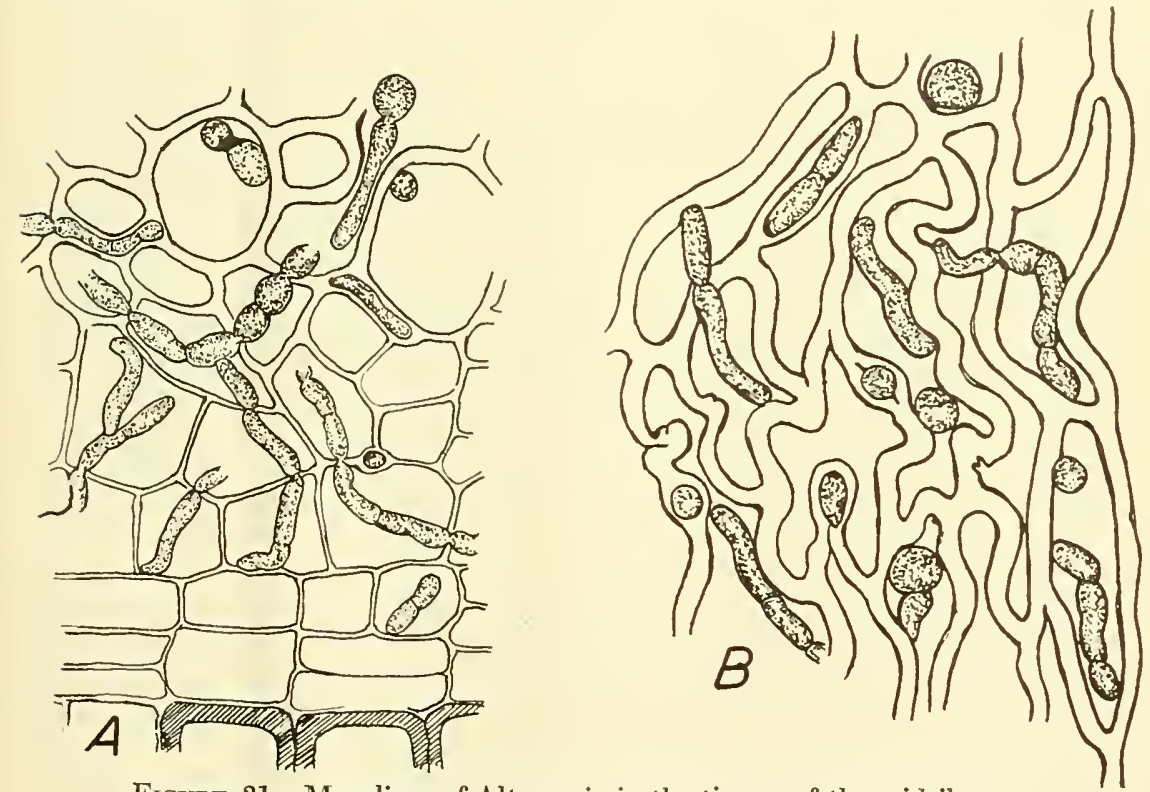

Figure 21. Mycelium of Alternaria in the tissues of the midrib.

A. In the phloem and cambium. B. In the collapsed cells of the cortex.

The hyphae continue to branch and spread until the tissues are filled with them. As stated above, in the early stages of invasion the cell walls of the host remain intact except where split apart by the hyphae passing between them. As the mycelium in the tissue becomes more concentrated, however, the walls begin to swell (gelatinize) until they are many times their original thickness. Numerous lamina become visible during this process and the swollen wall substance becomes more and more rarefied, taking the stain ever less deeply. This disintegration process, or gelatinization, continues until all the tissue is reduced to a thin, formless mass of slime in which the dense, tangled weft of hyphae is imbedded. 


\section{BROADLEAF FERTILIZER EXPERIMENTS}

\section{J. S. Owens ${ }^{1}$}

Until the initiation of this series of experiments in 1930, the then recent studies of the fertilization of stalk tobacco were confined almost entirely to the Havana type and were conducted at the Tobacco Substation at Windsor. The studies with Havana suggested several rather definite conclusions which were accepted by many growers of that type. While it was reasonable to assume that similar results would have been secured had Broadleaf tobacco been used and the experiments located in the heart of the Broadleaf district, it seemed best to test these assumptions by field trials.

The importance of sources and the quantity of potash required to grow good crops seemed so well established that no variations were made in the potash treatments. The amounts and sources used were intended to be sufficient for normal requirements.

In the case of nitrogen, which makes up a large part of the cost of tobacco fertilization, four treatments were planned with important relationships to economy. Two of these were to compare the relative merits, about which there has been much debate, of large proportions of cottonseed meal and castor pomace. Another concerned the use of urea, a lower cost nitrogen carrier which had just become an important commercial source. The fourth employed 150 pounds of nitrogen per acre, instead of the usual 200 , secured from a mixture of materials commonly used.

Trials at Windsor seemed to leave no doubt that more phosphorus is used on land which has been in tobacco for some time than is needed to raise Havana. In fact, the quantity of phosphorus furnished with the organic materials generally used to supply nitrogen appeared to be sufficient on soils in which there was a large accumulated reserve.

Four quantities were applied in these tests. They varied from that supplied by cottonseed meal alone ( 50 pounds phosphoric acid per acre) to an amount (300 pounds per acre) far in excess of that used even with liberal fertilization.

The first series of plots was laid out on the farm of Harry N. Farnham, East Windsor Hill, in the spring of 1930 . The field proved to vary too much in soil characteristics for valuable experimentation. The growth was erratic and did not show consistent response to the treatments. Root rot infestation added to the irregularities. Hail destroyed the crop near harvest time and neither yields nor valuable observations were secured.

The following spring, the experiment was transferred to a seemingly more uniform piece of land on the farm of Frank Roberts, East Hartford. The same fertilizer treatments were applied and crops harvested on the same plots in 1931, 1932, 1933, 1934 and 1936.

The field is almost level, the soil a Hartford sandy loam and considered by the owner to be uniformly good tobacco land. It had been in Broadleaf tobacco for many years before this experiment was started. It does not erode badly from either wind or water. During the experimental period a cover crop of barley was sown each year and plowed under about a month before setting the tobacco. The barley was a good protection from erosion but did not grow as large as it does on soils which hold moisture better.

\footnotetext{
${ }_{1}$ Professor of Agronomy, Extension Service, Connecticut State College, Storrs, Conm.
} 
The treatments and results for 1931 and 1932 have been reported previously' but will be summarized here. The plots, each one-twentieth acre in size, were arranged in three series. Hence, the same fertilizer treatment was repeated on three separate plots. The low nitrogen applications started in 1932 were an exception, there being only two adjacent plots at the east side of the field.

The plots with cottonseed meal as the chief source of nitrogen received the following:

\begin{tabular}{|c|c|c|c|c|c|}
\hline Materials per Acre & Pounds & $\mathrm{N}$ & $\begin{array}{c}\text { Nutrien } \\
\mathrm{P}_{2} 0_{5}\end{array}$ & $\begin{array}{c}\mathrm{cre} \\
\mathrm{K}_{2} \mathrm{O}\end{array}$ & $\mathrm{MgO}$ \\
\hline Cottonseed meal & 2,425 & 160 & 72 & 48 & 24 \\
\hline Nitrate of potash & 295 & 40 & & 130 & \\
\hline Sulfate of potash & 45 & & & 22 & \\
\hline Precipated bone & 72 & & 28 & & \\
\hline Magnesian limestone & 70 & & & & 14 \\
\hline Total & 2,907 & 200 & 100 & 200 & 38 \\
\hline
\end{tabular}

The high castor pomace plots were different only in that 3,200 pounds of castor pomace were used in place of cottonseed meal to supply the 160 pounds of nitrogen, the remaining 40 pounds of nitrogen being supplied by the nitrate of potash.

The other nitrogen source plots included 220 pounds of urea to supply 100 pounds of nitrogen or one-half of all the nitrogen. The remainder was supplied by cottonseed meal, 1,515 pounds per acre.

The low nitrogen formula and approximate nutrient content were as follows:

\begin{tabular}{|c|c|c|c|c|c|}
\hline Materials per Acre & Pounds & $\mathrm{N}$ & $\begin{array}{r}\text { Nutrient } \\
P_{2} 0_{5}\end{array}$ & $\mathrm{~K}_{2} \mathrm{O}$ & $\mathrm{MgO}$ \\
\hline Cottonseed meal & 1,300 & 86 & 39 & 26 & 13 \\
\hline Urea & 75 & 35 & & & \\
\hline Nitrate of potash & 240 & 32 & & 105 & \\
\hline Sulfate of potash & 150 & & & 74 & \\
\hline Hydrated lime & 70 & & & & 23 \\
\hline Precipated bone & 160 & & 64 & & \\
\hline Total & 1,995 & 153 & 103 & 205 & 36 \\
\hline
\end{tabular}

The phosphorus in each of the nitrogen test plots was kept at the uniform rate of 100 pounds phosphoric acid per acre and the potash at 200 pounds potash.

In the phosphorus series the plots with the lowest quantity of phosphorus received the following:

\begin{tabular}{|c|c|c|c|c|c|}
\hline Materials per Acre & Pounds & $N$ & $\begin{array}{l}\text { Nutrients per } \\
\mathrm{P}_{2} 0_{5}\end{array}$ & ${ }_{\mathrm{K}}$ Acre & $\mathrm{MgO}$ \\
\hline Cottonseed meal & 1,740 & 114 & 50 & 35 & 17 \\
\hline Urea & 100 & 46 & & & \\
\hline Nitrate of potash & 295 & 40 & & 130 & \\
\hline Sulfate of potash & 72 & & & 35 & \\
\hline Magnesian limestone & 100 & & & & 20 \\
\hline Total & 2,307 & 200 & 50 & 200 & 37 \\
\hline
\end{tabular}

${ }^{1}$ Conn. Agr. Exp. Sta. Bul. 350, Tobacco Substation Report for 1930. 
The other plots in this series were modified only to increase the phosphoric acid to 100,200 and 300 pounds per acre. This was done by increasing the quantity of precipitated bone, except for a few instances in which small amounts of bone meal or superphosphate were substituted. The nitrogen and potash sources were kept the same and supplied 200 pounds of elemental nitrogen and potash $\left(\mathrm{K}_{2} \mathrm{O}\right)$ per acre respectively.

Begimning in 1933, the $\mathrm{MgO}$ was approximately doubled by using more hydrated lime ( 80 pounds per acre) in both the phosphorus and nitrogen plots.

\section{Results from the Nitrogen Treatments}

The differences due to the use of cottonseed meal, castor pomace and urea as the principal sources of nitrogen were neither large nor very consistent. Each produced moderately good yields and quality.

An examination of the individual plots (see Table 19) will show that the three, N1A, N2A and N3A, which were adjacent on the west side of the field, yielded less each year than the others with the same treatments. Since one plot of each of the triplicates was low in yield (but usually not in grade value) the error tends more to reduce the average yield than to alter the effects of the differences in treatments.

If the individual yields for each plot of the three treatments are rated, the castor pomace treatment shows a decided advantage. It was highest in three years out of five. However, the actual yield differences between the pomace and urea plots are too small to conclude that one was much better than the other. The average yield on the cottonseed plots was 4 percent less than that on the castor pomace.

The average grade index shows practically no difference between the effects of cottonseed meal and castor pomace; the index from urea is only a little lower.

The plots with only 150 pounds of nitrogen per acre yielded as much tobacco as any of those receiving the regular applications of 200 pounds in the nitrogen series. The average was the same as that for the castor pomace plots but the grade index was a little lower. These treatments correspond closest to $\mathrm{P} 2$, the phosphorus plots which also received 100 pounds of $\mathrm{P}_{2} \mathrm{O}_{5}$ per acre, but 200 pounds of nitrogen from the same sources. This comparison shows only a very small gain for the full amount of nitrogen either in weight or grade index.

\section{Results from the Phosphorus Treatments}

Since the entire area used in the experiment had been fertilized for a long period previously, a large accumulation of readily available phosphorus could be expected. Soil tests taken just before the initial fertilization for the experiment seemed to verify this assumption. Samples from each plot taken subsequently showed what is considered to be a medium to good reserve. The accumulation increased during the experiment and was high on all plots in the spring of 1936.

However, there were moderate and consistent gains (see Table 20) for the 100-pound and 200-pound applications of phosphoric acid per acre over the 50-pound applications. There are some large irregularities in the individual plots but the frequencies of the larger yields over the 
Broadleaf Fertilizer Experiments

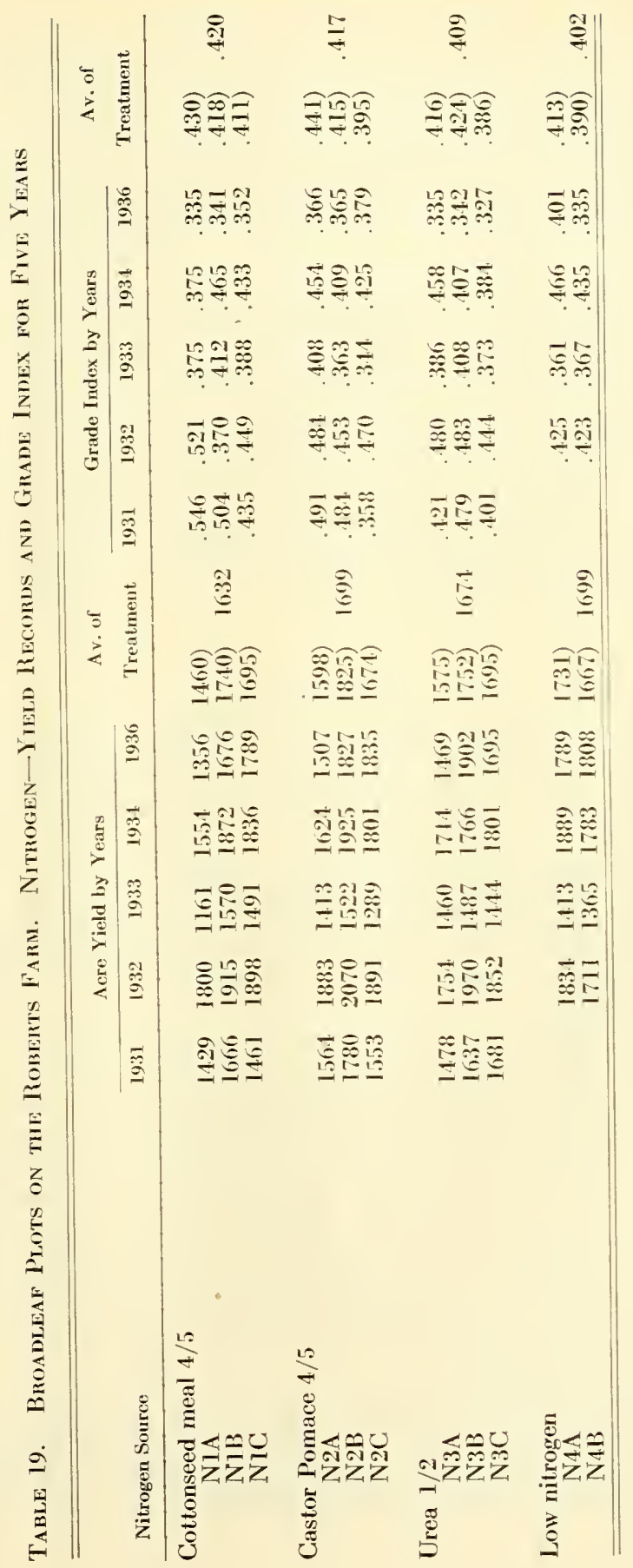


smaller ones are consistent with the averages. The only appreciable change in the grade index was for the 200 pounds of phosphoric acid. There are no indications that the 300-pound treatment was superior to the 200-pound and possibly not to the 100-pound.

It now seems probable that the high acidity which existed throughout the experiment was a disturbing factor, affecting the availability of the phosphorus in particular. A scarcity of calcium would cause the phosphorus to combine with iron and aluminum, making relatively insoluble compounds.

Lime was not applied at the beginning, even though the reaction was only $\mathrm{pH} 4.4$, because good crops were being grown. Soil samples taken from individual plots in the spring of 1932 showed a considerable decrease in acidity. The reactions varied from $\mathrm{pH} 4.6$ to $\mathrm{pH} 5.2$ with most of them around pH 5.0 and no apparent correlation to the treatments. In the spring of 1936 the acidity was higher again, $\mathrm{pH} 4.5$ to $\mathrm{pH} 4.8$, but the nitrate nitrogen was high at the time of sampling, making the acidity temporarily very high.

As might be expected with a coarse textured soil cultivated frequently, the organic matter content was low, around 3 to 4 percent, and an increase of about .5 percent from 1932 to 1936 .

\section{Conclusion}

Cottonseed meal and castor pomace were about equally satisfactory when each was used as the source of four-fifths of the nitrogen applied to Broadleaf tobacco. The slight difference in yield was in favor of the castor pomace.

A fertilizer mixture containing urea to supply one-half of the nitrogen and the balance from cottonseed meal gave yields only a little lower than the high castor pomace mixture and only a slight decrease in grade index. These good results seem to indicate that urea can be used to supply one-half of the nitrogen, a practice that will usually mean an appreciable saving.

The mixture supplying 150 pounds of nitrogen per acre gave practically the same results as a similar mixture which supplied 200 pounds. This cannot be interpreted as being applicable for all soils. Those which are coarse in texture and which do not retain moisture may need more nitrogen or at least supplemental applications during the growing season.

Under the conditions of this experiment, 50 pounds of phosphoric acid per acre were not sufficient. There is so little increase in yields for heavier applications that it is probable that with less acidity the 50 -pound or 100-pound application of phosphoric acid would have been sufficient. Many fields used for Broadleaf have less acidity and more reserve phosphorus than this one, consequently they do not need more than 100 pounds of phosphoric acid per acre.

Finally and probably most important of all, this series of tests shows no serious contradictions to the more exhaustive experiments with Havana at Windsor. Thus Broadleaf growers may safely use results from the fertilizer tests at Windsor as a basis for their own practices. 
Broadleaf Fertilizer Experiments

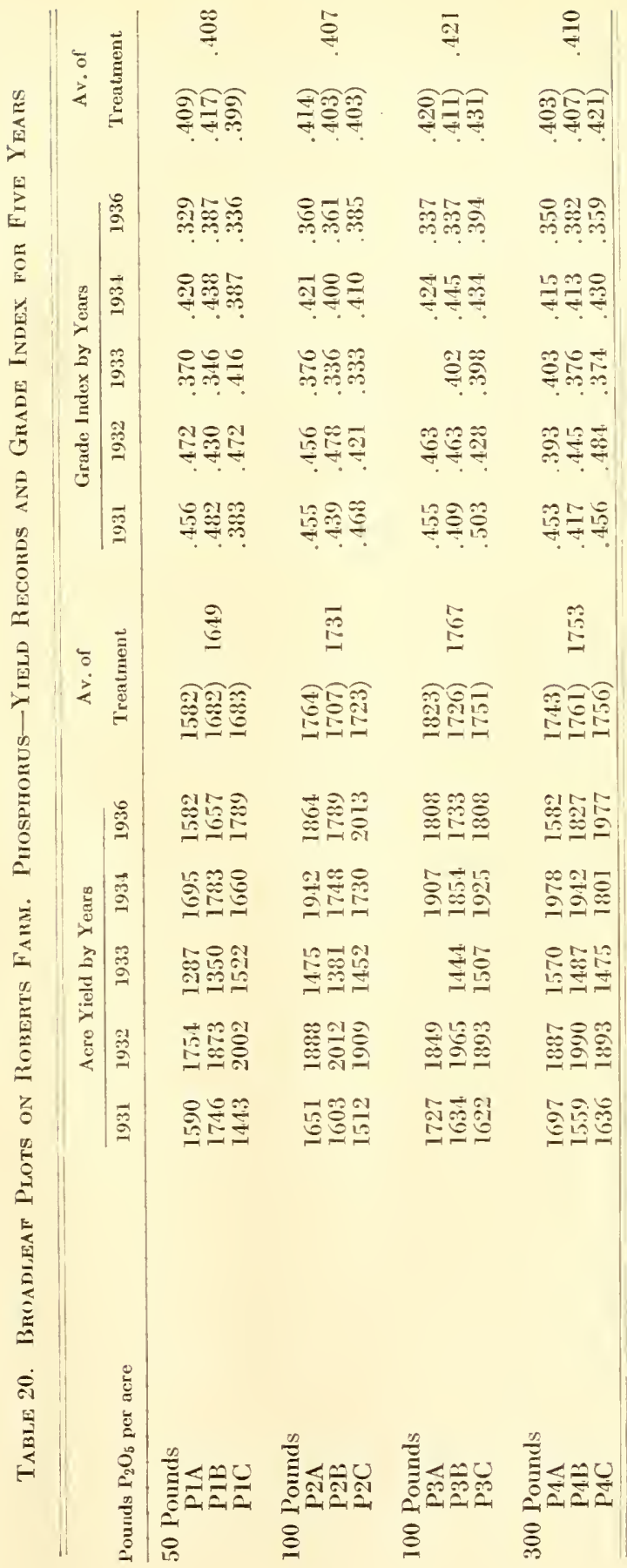


$5338 \quad 63$ 


University of

Connecticut

Libraries

|||||||||||||||||||||||||||||

$\mathbf{3 9 1 5 3 0 2 8 8 5 4 2 3 2}$ 
